\title{
From All American Girl to Fresh Off the Boat: Exploring the Relationship Between Media Representations and Identity Formation
}

\author{
by \\ Pam Lim
}

A thesis submitted to the Faculty of Graduate and Postdoctoral Affairs in partial fulfillment of the requirements for the degree of

Master of Arts

in

Communication

Carleton University

Ottawa, Ontario

(C) 2017, Pam Lim 


\begin{abstract}
When ethnic and racial groups are absent from Hollywood narratives, the subtext is they don't matter. This thesis explores how diverse images of Asian Americans and Canadians in media are decoded for meaning and the impact of this process on one's identity. Employing a qualitative methodology, this thesis supports the idea that the media play a significant and influential role in identity development. The findings suggest that young adults: (1) rely on stereotypes to make sense of Asian American and Canadian representations in media; (2) downplay the influence of media by separating racial ideology from media production, content, and consumption; and (3) struggle to understand their ethnic, racial, and national identity in the context of Canadian multiculturalism. This thesis contributes to scholarship on race, media, and Asian identity by linking significant changes in the culture industries, like the recent move towards diversity, to the study of media effects among Asian Canadians and by expanding the relationship between multicultural discourse and Asian Canadian identity.
\end{abstract}




\section{Acknowledgements}

I would like to thank a handful of people because without them this wouldn't be possible:

My supervisor, Dr. Benjamin Woo, for your patience, for encouraging me to think about representation in different ways, and for motivating me to write beyond what I thought I was capable of.

Dr. Merlyna Lim for your valuable insights and wonderful sense of humour.

My committee members and the Communication and Media studies faculty and administrative staff for their time, expertise, and guidance.

My colleagues for being welcoming, supportive, and inspiring. You've been so kind and have made this experience one I won't forget.

The seventeen individuals who participated in this study for sharing your time, energy, and stories with me.

Lastly, my close friends and family. We did it. 


\section{Table of Contents}

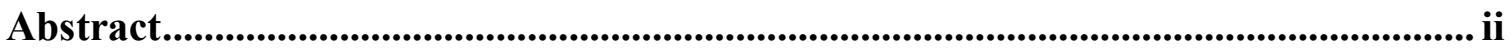

Acknowledgements ........................................................................................................................... iii

List of Tables ............................................................................................................ vi

List of Appendices........................................................................................................................ vii

1 Chapter: Introduction: Representation in Media.................................................... 1

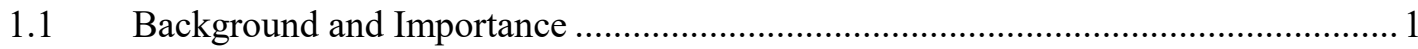

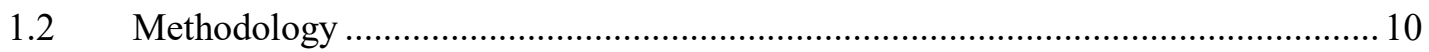

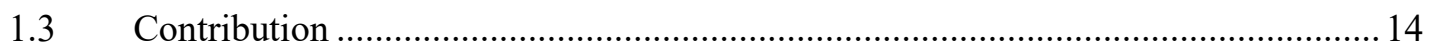

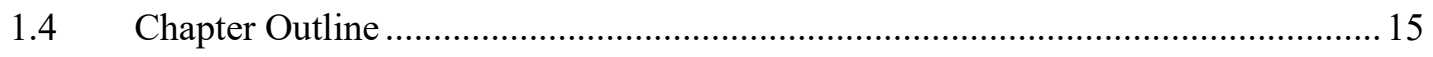

2 Chapter: Methodology....................................................................................... 17

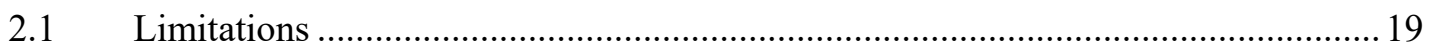

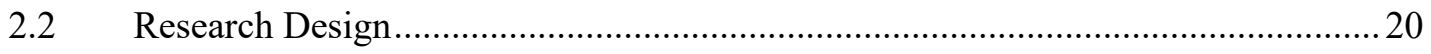

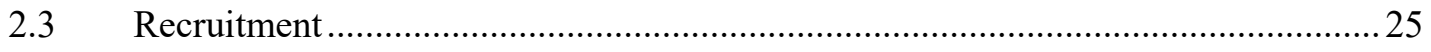

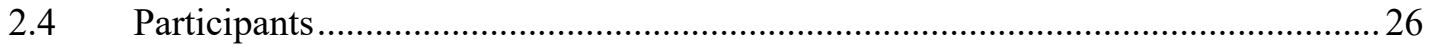

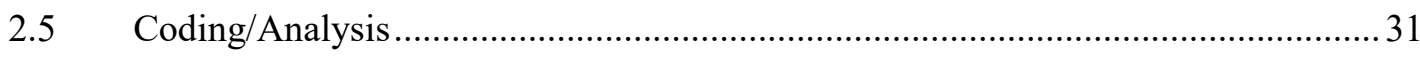

3 Chapter: Making Sense of Asian American and Canadian Representations . 37

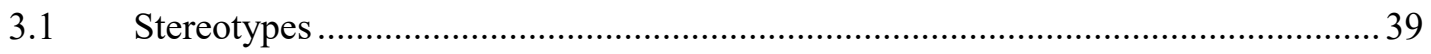

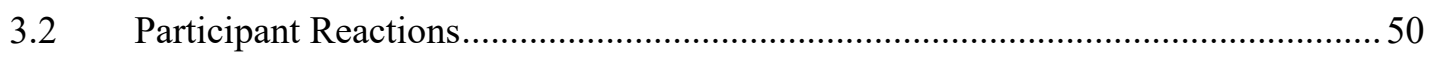

3.3 Downplaying Asian American and Canadian Representations................................55

4 Chapter: Identity ........................................................................................................... 62

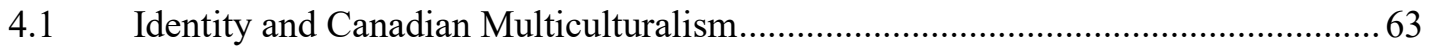

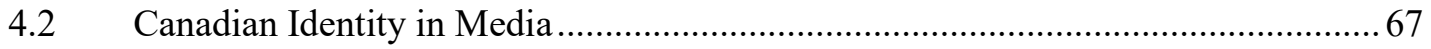

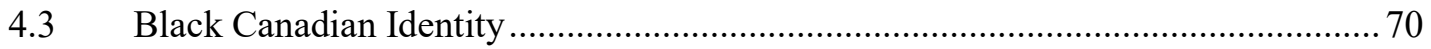

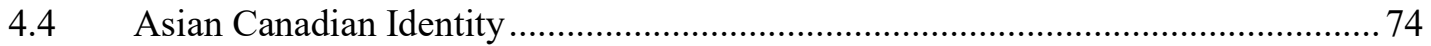


5 Chapter: Conclusion .............................................................................................. 81

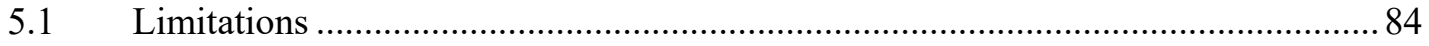

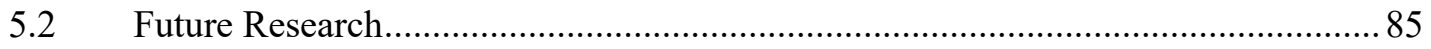

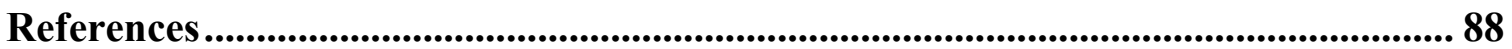

Appendices..................................................................................................................... 100

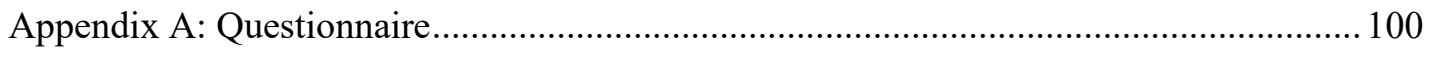

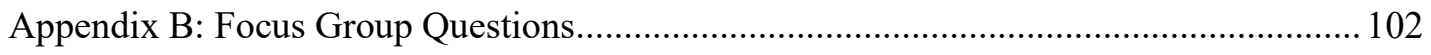

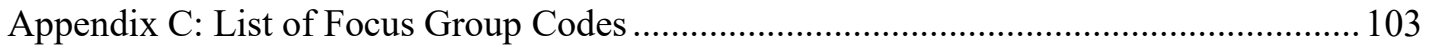

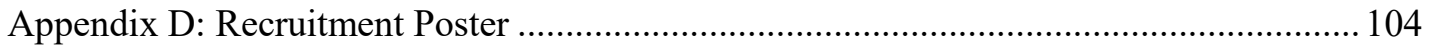




\section{List of Tables}

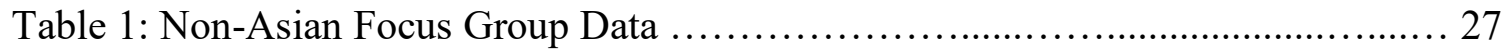

Table 2: Asian Focus Group Data .................................................................. 29

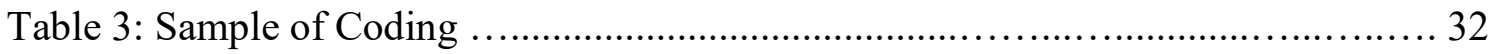




\section{List of Appendices}

Appendix A: Questionnaire .............................................. 100

Appendix B: Focus Group Questions ........................................ 102

Appendix C: List of Focus Group Codes .................................... 103

Appendix D: Recruitment Poster ............................................. 104 


\section{Chapter: Introduction: Representation in Media}

Culturally, [Asians] are in an ice age. We don't even have fire. We don't even have the wheel. If [Fresh Off the Boat] can be the first wheel, maybe others can make more.

- Eddie Huang, 2015 as cited in The New York Times Magazine

\subsection{Background and Importance}

After a twenty-year absence, since the cancellation of Margaret Cho's AllAmerican Girl (1994), there is once again an Asian American family sitcom on network television. Recently renewed for a fourth season, ABC's Fresh Off the Boat has been described as a watershed moment in television history (Ho, 2015). Based on Eddie Huang's memoir, Fresh Off the Boat portrays Asian Americans as central figures in mainstream America, not as the sidekick or as the butt of jokes, but as complex individuals (Rao, 2016). Groups that are marginalized now account for one third of series regulars on US network TV (Townsend, 2015), and in 2015, ABC became the first network to air three Asian-led shows in a single season, Fresh Off the Boat, Dr. Ken, and Quantico (Ge, 2015). These shows acknowledged the Asian American experience and confronted the erasure of Asians from a "powerful medium that wouldn't give them the time of day for decades" (Rao, 2016, para. 2). In comparison to film, which was at the time embroiled in controversies related to racial representation and casting, television seemed to embrace diversity and the realities of race making this a particularly interesting moment to examine its cultural influence.

Race and ethnicity represent one of the most "challenging and controversial issues of the twenty first century" (Mastro, 2015, p. 1). Just look at some of the biggest 
headlines from the past few years: the Black Lives Matter movement, the missing and murdered Indigenous women of Canada, and the role of Islamophobic rhetoric in the United Kingdom's withdrawal from the European Union all highlight racial tensions and our inability to see past perceived physical differences. The relationship between race, media, and identity is complex, and these issues have been researched through various disciplines such as communication, cultural studies, geography, linguistics, political science, psychology, sociology, and women's studies. Many studies have explored the effects of television in our lives (Alexandrin, 2009; Coltrane \& Messineo, 2000; Mastro, 2015). These studies generally approach the topic through social learning theory or cultivation theory. Social learning theory posits behaviours can be learned by watching others (Bandura, 2002). Cultivation theory argues repeat exposure to media can influence real world perceptions (Comstock, 1993; Gerbner, Gross, Morgan, Signorielli \& Shanahan, 2012). That is, individuals start to believe that TV is a reflection of real life. Both theories support the idea that TV plays a significant role in shaping how we understand ourselves, society, and our place within it. Coltrane and Messineo (2000) found that "consciously and unconsciously, people rely on television imagery to interpret and understand their daily lives" (p. 385). TV acts as a " lifelong educator" and through its repetitive images, stories, and meanings it shapes "people's beliefs and attitudes, values, perceptions, and knowledge" (Alexandrin, 2009, p. 150). And in the absence of direct contact or when contact is limited, television can teach individuals about various groups of people (Mastro, 2015).

By contrast, there are also theories that differ or reject this point of view. Social determinism argues that technology is shaped by social relations. The theory suggests 
that media are created by society in order to fulfill a need. For example, television was created to fulfill the need for visual and audio communication. Often needs are determined by the wealthy because they have the power to influence and capital to fund research development. Other scholars, like Stuart Hall, view media as part of a complex circuit where societal values and norms help create cultural representations (1997). Hall viewed audiences as both the "source" and "receiver" of TV messages because their feedback is incorporated into production (Hall, 1980, p. 92). These three overlapping perspectives offer insights into the complex relationship between media, society, and technology.

The importance of representation and the way social groups are represented in media has also been well documented (Mastro, 2015; Mastro \& Greenberg, 2000; Tukachinsky, Mastro, \& Yarchi, 2015). Spencer describes representation as the "social process of making sense of the many signifying systems within a culture" (2014, p. xviii). It shapes how we organize, regulate, and understand our place in society. Hall (1997) argues images themselves do not have any inherent or fixed meanings, instead the way we use, think, say, or feel about objects, things, or ideas is what gives meaning. Racial representations are powerful because they "call our very identities into question" by defining "what is 'normal,' who belongs and therefore, who is excluded" (Hall, 1997, p. 10). Studies from around the world indicate that negative representations of racialized groups are a common occurrence. Muslims are negatively depicted in the United Kingdom, Turkish individuals in Germany, and Arabs in Israel (Tukachinsky, Mastro \& Yarchi, 2015, p. 34). Constructions of race are unstable and constantly shifting (Hall, 1997; Spencer, 2012), but mainstream media routinely underrepresent and stereotype 
communities that have been marginalized. Molina-Guzman's research (2016) notes mainstream media support "homogeneity, structural stability, and binary representations of otherness" (p. 411).

But stereotyping or generalizing as a cognitive activity serves an important function (see section 3.1) (Lippmann, 1922; Schneider, 2004). It helps us categorize and quickly make meaning, but problems arise when these stereotypes are false and used to make incorrect judgements. The media play a significant role in perpetuating stereotypes but they don't create them. Stereotypes are usually rooted in history. Studies tracing the historical context of common Asian stereotypes found that dominant groups in society often created these images to erase or justify their oppressive behaviours (see section 3.1.1) (Hamamoto, 1994; Li, 1998; Marchetti, 1995; Ono \& Pham, 2009; Shim, 1998; Sun, Liberman, Butler, Lee, and Webb, 2015; Wu, 2003). Reinforcing negative images of groups that have been racialized serves the interests of dominant social groups by maintaining their hegemony (Boggs, 1976; Henry \& Tator, 1999; Lull, 1995). These images reinforce the status quo and perpetuate dominant groups as naturally superior (Mahtani, 2001; Sun et al., 2015, p. 296), but this has devastating effects on the communities that are marginalized because their cultural, political, economic, and social power is neutralized.

Research linking media images to identity formation suggests one's sense of identity or "subjective personhood" is constantly shifting and that a number of factors like social interactions, social demographics, and media images can impact the way someone identifies (see section 4.1) (Huntemann \& Morgan, 2001, p. 305). Negative images are associated with negative psychological impacts such as low self-esteem and 
low self-confidence (Leavitt, Covarrubias, Perez, \& Fryberg, 2015; Schmader, Block, \& Lickel, 2015). In Canada media representations are further complicated because policies, like the Multiculturalism Act, mandate and promote multiculturalism (see section 4.2). Mahtani's Canadian study found the exclusion and marginalization of social groups teach society that these groups are "threatening, deviant and irrelevant to nation building" (2001, p. 100). Moreover, these depictions damage the psyches of groups that have been marginalized by creating inferiority complexes (p. 100). Baker (1983), Collins (1990), and Hamamoto (1994) suggest these representations act as a form of psychosocial dominance and control because of the subtle way prevalent images are internalized. Stereotypical portrayals in media may result in a high degree of racial self-hatred in Asian individuals (see section 4.4) (Adachi, 2006). They may have limited aspirations, experience internal conflict, and reject their ethnic heritage in favour of the dominant culture (Kim, 2012).

There are two general approaches to improving or counteracting negative depictions. The first is to diversify. Media representations are often a reflection of their creators. White men are overrepresented in media industries, particularly in influential executive positions (Smith, Choueiti \& Pieper, 2016). The Comprehensive Annenberg Report on Diversity and Entertainment (CARD) suggests increasing the number of individuals from diverse backgrounds in positions of power is one way media can work towards improving representations on screen (Smith, Choueiti \& Pieper, 2016, p. 17). CARD also suggests that making inclusion goals public and transparent, being able to recognize and move away from stereotypical thinking, and monitoring progress and evaluation will aid in improving media representations (Smith, Choueiti \& Pieper, 2016, 
p. 17). It's a start but not a long term solution. Ethnic minorities may have internalized societal norms and thus the same kind of stories are retold (Dates \& Stroman, 2001). Also media representations are influenced by societal norms and values (Hall, 1992, p. 14). Therefore, change needs to include "economic, social and political structures" (MolinaGuzman, 2016, p. 411). The second approach is to use media literacy to mitigate the effects of negative representations (see section 3.3). Media industries are slow to diversify and it's difficult to enforce media regulations on racial and ethnic depictions (Tukachinsky, 2015). Some researchers call for the implementation of a more comprehensive media literacy curriculum in schools and universities to give individuals the analytical tools necessary to comprehend media messages (Coltrane \& Messineo, 2000; Hobbs \& Jensen, 2009; Lewis \& Jhally, 1998; Scharrer \& Ramasubramanian, 2015). These two approaches or some combination of them are generally viewed as necessary steps in order to improve media representations.

Three areas currently being investigated in field of race and media include: (1) identifying the kinds of media representations that can prompt positive attitudes; (2) determining whether there are similarities across different cultures; and (3) studying the implications of an increasingly digital society (Tukachinsky, 2015, p. 188). A few studies tackling these issues include Tukachinsky (2015) and Ramasubramanian's (2015) (see pp. $7-8,38-39)$ work on using positive images to promote positive attitudes and feelings, Harwood and Vincze's (2015) study on ethnolinguistic identity in various cultural groups such as German, Hungarian, and Swedish minorities in Europe, and Molina-Guzman's (2016) study on the impact of digital streaming services on traditional media (see page 84). 
But there are also gaps in the current academic literature. Asians are often excluded from content analyses of race and ethnicity in mainstream media. Tukachinsky, Mastro and Yarchi's (2015) study on the role of media in relation to race and ethnicity argues mainstream media depictions of Asian Americans are so uncommon (one to three per cent of characters on TV) that "it's not possible to examine the effects" because of "a lack of data" and "negligible numbers" (p. 35). Studies on representations of racialized groups tend to focus on the black/white paradigm (Hunt, 2002), Hispanic Americans (Greenberg \& Baptista-Fernandez, 1980), or the way dominant groups make sense of racial and ethnic depictions as opposed to members of those groups themselves (Tukachinsky, Mastro \& Yarchi, 2015). Many have researched the history of Asian stereotypes (Hamamoto, 1994; Marchetti, 1995; Ono \& Pham, 2009; Shim, 1998; Wu, 2003) but few link Asian media representations to identity formation. The small amount that do have focused on the model minority myth in academic and professional settings (Cheryan \& Bodenhausen, 2000; Lee, 2015), the impact of western beauty standards (Mok, 1998), sexual discrimination among Asian American women (Chan, 1988), the sexuality and attractiveness of Asian American men (Chan, 2001), online dating preferences of Asian Americans (Tsunokai, McGrath \& Kavanagh, 2014), and the way Asian American college students make sense of Asian representations in the digital era (Sun et al., 2015). Overall, there is a small amount of research being done on Asian Americans and Canadians in mainstream media. The relationship between Asian representations in media and identity formation is particularly limited in size and scope.

Another gap, which is currently being studied, is the lack of research on using positive images to offset normalized stereotypes and reduce prejudice. Greenberg's 
drench hypothesis (1998) and Ramasubramanian's (2015) and Tukachinsky's (2015) work on counter exemplars in media suggest it is difficult but possible. Greenberg's Drench hypothesis suggests that a few "critical images" can potentially have a greater impact on influencing attitudes than more common and frequent images. Ramasubramanian's (2015) and Tukachinsky's (2015) approach focuses more on common images. They suggest in order to reduce prejudice: (1) there must be a diverse range of positive images to avoid subtyping, and (2) the images must carefully pull from recognizable features without stereotyping. Subtyping is when positive representations are dismissed as being "underrepresentative" or viewed as exceptions to the rule (Bodenhausen, Schwarz, Bless, \& Wanke, 1995; Richards \& Hewstone, 2001). If there are many different positive examples they become harder to dismiss. For instance, if you're trying to counteract the nerd stereotype through representations of Asian Americans and Canadians as social and charming it may lead to the creation of a new subgroup, like "cool Asians," as opposed to offsetting the stereotype entirely. To avoid this, diverse examples are necessary (Hewstone, Johnston \& Aird, 1992). Representations consistent with stereotypes have more success in improving attitudes because people need to see recognizable features in order to illicit a positive response (Tukachinsky, 2015, p. 189). The challenge is figuring out how to use familiar images without stereotyping.

For Asian Americans and Canadians this is particularly difficult because media images of Asians are overwhelmingly negative and disparaging. But there have been breakthroughs recently. History shows public outcry and advocacy are successful at forcing media industries to change (Tukachinsky, 2015, p.195). The recent \#OscarsSoWhite controversy serves as an example of this. When the Academy of Motion 
Picture Arts and Sciences announced back-to-back all white acting nominees during the 2015 and 2016 Academy Awards the reaction was overwhelmingly negative. The social media campaign, \#OscarsSoWhite, went viral and high profile celebrities chose to boycott the awards ceremony. Cheryl Boone Isaacs, president of the Academy, released a statement saying, "it's time for big changes" and promised that the Academy would "conduct a review of [their] membership recruitment in order to bring about muchneeded diversity in [their] 2016 class and beyond" (Boone Isaacs, 2016). Through a voting process the Academy's members determine Oscar nominees and winners. In June of 2016, six-hundred and eighty-three new professionals were invited to join the Academy, making it the largest and most diverse class in its ninety year history. Of the new class forty-six per cent were women and forty-one were people of colour (Rottenberg, 2017, para. 9). The following year at the 2017 Oscars seven non-white actors, Viola Davis, Naomie Harris, Mahershala Ali, Ruth Negga, Denzel Washington, Dev Patel, and Octavia Spencer, were nominated for acting awards. These events show how public opinion can lead to changes in an industry. Public outcry and social media activism, like \#OscarsSoWhite, \#WhitewashedOUT, \#StarringConstanceWu, and \#StarringJohnCho, have pushed the cultural industries to make changes. The \#OscarsSoWhite controversy and subsequent backlash have pushed the importance of media representation to the forefront of diversity discussions. But because television moves at a quicker pace and appears to be embracing diversity faster than film, it provides a better area of study with greater variety. It's also important to monitor the way individuals themselves are reacting to these changes, in particular young Canadians who 
are more diverse that previous generations and who are in the midst of a pivotal moment in terms of their identity development.

This thesis approaches issues of media, race, and representation by discussing how university students make sense of diverse images of Asian Americans and Canadians in mainstream media. This project has two research questions:

Q1. How do Canadian university students make sense of diverse images of Asian Americans and Canadians on network and web television series?

Q2. How do representations of ethnic and racial identity in mainstream media impact the identity of Canadian university students?

\subsection{Methodology}

I selected focus groups as a method to research this topic. First, because the method lends itself well to investigating how and why people may feel a certain way. Second, I felt the group dynamic mimicked authentic everyday communication processes and offered insights into how ideas are formulated and built upon during discussions with others. I chose television to investigate these issues because of its flexibility. While there is a lack of diversity in both TV and film, television fares slightly better. Both are predominantly controlled by six major studios: Fox Entertainment Group, Paramount Motion Pictures Group, Sony Pictures Motion Picture Group, Universal Studios, Walt Disney Studios, and Warner Bros. Entertainment, but the TV industry is significantly larger (network, cable, streaming services) and moves much faster. There are more opportunities to tell different kinds of stories. By comparison, films take much longer to make and are more expensive. Studios and investors are often reluctant to invest in "unproven" talent, which is often associated with ethnic minorities. The film industry 
tends to release fewer films and focus on blockbusters. Television offers a richer source of positive and diverse representations making it more suitable for this study.

I chose five TV clips that showcased a range of Asian American and Canadian experiences in mostly non-stereotypical ways. ${ }^{1}$ These clips from critically and commercially successful television shows such as Fresh Off the Boat, Community, Kim's Convenience and Master of None repositioned recognizable features, like stereotypes, in smart and self-reflexive ways. The purpose of the clips was to generate conversation. Other researchers have used this method as well. For example, Tobin's (1995) study used focus groups to investigate the impact of sexist, racist, and violent images on children. Tobin used clips from Swiss Family Robinson that dealt with these issues and then studied the children's reactions. I anticipated that Canadian university students would react positively to recent representations of Asian Americans and Canadians because the selected clips met the general criteria from Ramasubramanian (2015) and Tukachinsky's (2015) work on prejudice reduction and counter exemplars in media. However, the purpose of clips was not to reduce prejudice. Additionally, because studies and reports indicate that diversity and media literacy are important areas for secondary and post secondary education, I felt participants would be conscious of ongoing struggles for inclusion in media and posses the critical and analytical skills necessary to make sense of texts in meaningful ways.

\footnotetext{
${ }^{1}$ The clip from All American Girl has been criticized by media critics and the public for its stereotypical portrayal but I felt it was important to included the clip for context and comparison. All American Girl was the first Asian American sitcom on prime time television. It was considered revolutionary during its time and it shows how things have changed in the last twenty years.
} 
I chose to focus on youths because they are increasingly more diverse than previous generations. The population of foreign born Canadians continues to rise as does the population of Canadian born children of immigrants (Statistics Canada, 2011). The lack of diversity in North American media may resonate more with younger generations because a greater number of them "face the challenge of developing a sense of themselves as members of an ethnic minority group while simultaneously becoming a member of the broader Canadian society" (Costigan, Su \& Hua, 2009, p. 261). Additionally, youths are in the process of understanding and exploring their ethnic identity. Yon's (2000) study on students at a Toronto high school found that youths "demonstrated tremendous flexibility" in their identity (p. 144). Through a series of ethnographic snapshots, Yon describes how youths can identify with many things or shift their ethnic and racial identity to their benefit. For instance, Yon illustrates how a "proud" black student can identify as black but also as "white" because of friendships with other white students (p. 154). Identity can be used "strategically and deliberately by youth to achieve particular goals in specific situations" (Sundar, 2008, p. 225). Sundar suggests students assess situations and then decide which aspect of their identity will help them achieve material/economic or emotional/physiological goals. For example, through a series of interviews, various South Asian youths describe how they "brown it up" or "bring down the brown" depending on the context (p. 265). While physical attributes associated with ethnicity and race act as visible markers, existing studies suggest Canadian youth may also adopt various identities or move between different identities depending on their situation. Social relationships, physical location, ethnic and cultural 
heritage, or interactions with cultural signs and symbols may contribute to how someone identifies.

Many scholars note the importance of reflexivity when conducting qualitative research (Cresswell \& Poth, 2017; Ortlipp, 2008). That is, writers need to understand and reflect on their own biases, values, and experiences that they bring to a research project (Cresswell \& Poth, 2017). This helps make the research process more transparent and visible (Ortlipp, 2008). My research in race, identity, and media stems from a personal interest. I wanted to know how and why race became so powerful. But more selfishly I wanted to know if others felt like me, if others fumbled through the same confusing experience of belonging and not belonging. My experiences of rarely seeing diverse representations of Asians on TV have influenced the way I approached this research. While trying to be objective, I realize it's difficult to separate my own biases, attitudes, and beliefs from my analysis and understanding. Therefore, I recorded reflexive comments and observations during the coding process. Through a series of focus groups, I came to three major conclusions:

I. Participants used stereotypes as a way to understand and make sense of media representations of Asian Americans and Canadians on network and web television series. Stereotypes provided a frame of reference to help participants situate their thoughts and opinions. East Asian participants felt the clips reinforced stereotypes, while non-Asian participants read the clips in ways consistent with stereotypes even when none were present. In both instances, participants used well known Asian stereotypes as a map to make sense of current, more diverse examples of Asian representations. 
II. Some participants downplayed the role of the media in shaping our worldview. They argued building a healthy sense of self and identity is one's own responsibility, not the media's responsibility. They felt media industries had the right to make a profit and the right to artistic freedom, even if that meant using stereotypes or creating disparaging images of groups that have been marginalized.

This perspective highlights the importance of media literacy.

III. Most participants struggled with understanding their racial, ethnic, and national identity especially in the context of multicultural nations like Canada where diversity is mandated through public policies. Participants felt this offered a superficial sense of belonging, and those who identified as non-white felt their national identity was denied. East Asian participants displayed behaviour consistent with Cheryan and Monin's (2005) phenomenon of identity denial and Jean Kim's (2002) Asian America Racial Identity Development theory (AARID), while black participants displayed a stronger desire to identify with their African or Caribbean heritage.

\subsection{Contribution}

This thesis makes two contributions to existing scholarship on race, media, and Asian identity. First, it links significant changes in the culture industries, such as the move towards more diverse Asian American and Canadian representations, to the study of media effects among Asian Canadians. For the first time in over a century, Hollywood appears to be embracing diversity. For the last few years headlines from alternative and mainstream media like, "2015: The Year Asian Americans Finally Got a 
Shot on TV" (Jung, 2015), "Asian Americans are Fighting for Visibility. They Will Not be Ignored." (Hess, 2016), "Why Television is Embracing Diversity and the Realities of Race"(Ryan, 2016), and "2016 was TV's Most Diverse Year Ever - and not Coincidentally, one of its Best" (Kang, 2016) have become common and reoccurring. This project explores how Asian Canadians are responding to these changes. Second, this thesis contributes by expanding on the relationship between multicultural discourse and Asian Canadian identity. A better understanding of why Asian Canadians feel like outsiders in their own homes provides valuable information to an underdeveloped area. Addressing the role that media play in identity denial calls attention to normalized practices and systemic racism. Hopefully, highlighting the effects of underrepresentation and stereotypical representation can lead to a more equal and inclusive approach from the Canadian media industry.

\subsection{Chapter Outline}

This project seeks to better understand how Asian Canadians construct identity, how representations are decoded for meaning, and the impact of this process on one's experiences, actions, perceptions, and sense of self. Chapter one outlines the project's methodology. Chapters two and three discuss the findings: chapter two addresses the role of stereotypes, contextualizes the history of Asian stereotypes in mainstream media, and examines participant reactions to Asian American and Canadian representations; chapter three unpacks how participants made sense of their racial, cultural, ethnic, and national identity in relation to media images and multicultural discourse. Lastly, chapter 
four concludes by discussing the relevance of the findings and offers recommendations for future research.

While researching this project I kept going back to activist Marian Wright Edelman's popular quote, "you can't be what you can't see," which, for me, reinforces why representations in popular culture are important and worth studying (Siebel-Newsom \& Costanzo, 2011). Gerbner and Gross explain "representation in the fictional world signifies social existence; absence means symbolic annihilation" (1976, p. 182). When you're "absent from the stories a nation tells about itself" (Hunt, Ramon \& Price, 2014, p. 5), the subtext is "you don't count" and that's damaging to one's sense of self (Boboltz \& Yam, 2017, para. 19). When groups are underrepresented "inequality is normalized and is more likely to be reinforced over time through our prejudices and practices" (Hunt, Ramon \& Price, 2014, p. 5). Seeing people like yourself succeeding or positively represented shows you what's possible. All American Girl paved the way by showing people that an Asian-led sitcom is possible. And Fresh Off the Boat proved an Asian-led sitcom could be critically and commercially successful. Diversity sells but more importantly it tells countless individuals that they matter and maybe, like Huang hopes, others will make more. 


\section{Chapter: Methodology}

You can learn a lot by listening to the stories people tell. The details they choose to share, the finer points they skirt around, and the way they speak - even their choice of words -reveals much about how they make meaning. Hall refers to language as a "privileged medium" because it's the way meaning is made, shared, produced, and communicated (1997, p. 2). Whether telling stories or discussing the news of the day, we make sense of things through the use of language. To understand the role race plays in the lives of young adults I wanted to listen to their stories, see them communicate in group settings, and watch them make meaning in relation to other people and their surroundings.

Focus groups are a form of group interview or discussion organized around a specific topic. There are many strengths and advantages in using this method. It is commonly used in ethnic minority studies because it allows researchers to gather a diverse group of individuals to focus on specific cultural norms (Kitzinger, 1995). Focus groups can reflect the attitudes and social realities of a specific cultural group.

Researchers also have "direct access to the language and concepts participants use to structure their experiences" (Hughes \& DuMont, 1993, p. 776). For example, Bullock and Jafri's (2001) study uses focus groups to discuss how Muslim women are often excluded from Canadian constructions of identity in media. The focus groups revealed nuanced information about the way Muslim women felt such as how negative images of Muslims led to "crises of self esteem, confusion about identity and doubt about one's faith." Participants explained that being forced "to question who you are all the time" made them stronger, more knowledgeable, and proud of their backgrounds (p. 38). Bullock and 
Jafri's study bridges the gap between media, non-Muslim Canadians, and Muslim women. The input from Muslim women themselves is vital to creating a more comprehensive understanding of how to diversify current media representations. Another example is Sue, Bucceri, Lin, Nadal and Torino's (2007) study which uses focus groups to study racial microaggressions among Asian Americans. The method enabled Sue et al. to uncover in-depth information from Asian Americans themselves to better understand how subtle forms of racism work to deny Asian American identity and perpetuate the model minority myth (p. 87).

This thesis uses focus groups to study how Canadians construct racial identity from media images for two main reasons: first, the method can be used to understand what participants think and how and why they might feel this way (Kitzinger, 1995). Content analysis is another method that is commonly used when studying groups that are racialized in media. It's effective in quantifying that media underrepresent and stereotype racialized groups but it doesn't account for the opinions of those groups or society at large. The second rationale for selecting this method is the explicit use of group interaction. Unlike one-on-one interviews, participants are encouraged to engage with one another, to share their experiences and ideas, and then build on them through discussions. This mimics authentic, interpersonal communication processes, like joking, arguing, and teasing, that we experience in everyday social settings (Kitzinger, 1995; Liamputtong, 2011). Through focus groups I can identify "shared and common knowledge" amongst different cultural groups (Kitzinger, 1995, p. 300). Focus groups also offer a more relaxed environment that welcomes conversations as opposed to interviews, which may feel more formal and direct. This is important because Glaser 
(1965) asserts that when researching social issues participants are more likely to be uncomfortable and as a result they may be dishonest. Therefore, watching or listening to people in relaxed environments is one of the few ways researchers can obtain relatively accurate data (p. 436).

\subsection{Limitations}

But there are limitations and concerns when conducting focus groups. Due to the group format, confidentiality is compromised. Researchers can remove identifiable information from final reports but they cannot guarantee that all research participants present during the session will adhere to confidentiality agreements. As a result, participants may be less willing to express themselves or to be honest. Focus groups have also been criticized for producing trivial results. Participants may be persuaded by other research participants or fabricate experiences in order to be perceived a specific way (Krueger \& Casey, 2014). For example, when discussing race and identity, participants may feel pressure to agree with statements for fear of being labeled "racist" or "overly sensitive." Another concern is the emergence of ideas that participants do not agree with. This could result in participants remaining silent because they do not want to challenge the majority or in conflict if they choose to confront others. Additionally, group participants can cue one another to focus on certain topics, while ignoring others, or frame issues a certain way (Hughes \& DuMont, 1993, p. 780). Some of these limitations are difficult to foresee or control, but moderators can defuse conflicts and try to give each participant an opportunity to speak. Despite these limitations, focus groups still provided the best option for this study because of the direct access to the concepts, language, and 
opinions of a specific cultural group. I needed input from Asian Canadians themselves to better understand the role of representation and racial identity in their lives.

\subsection{Research Design}

Two ninety-minute focus groups were conducted: one session with students who self-identified as Asian, specifically Chinese, Filipino, Indian, and Punjabi, and the other with a non-Asian group of students who self-identified as black, white, and biracial. ${ }^{2}$ Separating the groups by race and ethnic identity allowed for: (1) a comparison to be made between students identifying as Asian and those who do not, and (2) for Asian identifying students to more easily express their concerns about the way they are represented in media. If participants feel they can relate to one another they may be more willing to share. My presence, as a grad student or as a person of Asian descent, may have impacted the way participants behaved. But I tried to be as neutral as possible and limit my interactions with them. I stressed that there was no "right answer", I didn't react to comments I didn't agree with, and I encouraged participants to speak honestly. Due to some of the remarks (see section 3.2 and 3.3), I felt that participants were forthcoming and didn't censor themselves in relation to my presence.

\subsubsection{Television Clips}

During the focus group I screened five clips from contemporary Asian led television shows. The clips, except for All American Girl which serves as a basis for comparison, met the general criteria from previous studies on media images as a form of prejudice

\footnotetext{
${ }^{2}$ There was one participant who identified as South Asian. Due to a miscommunication, I was unaware of this participant's racial identity but I allowed them to participate. For consistency, I would have preferred to place this participant in the Asian focus group.
} 
reduction. The clips incorporated criteria from both Ramasubramanian (2015) and Tukachinsky's work (2015), although they were not designed to elicit a positive response from participants. The clips were diverse, non-stereotypical, and repositioned familiar narratives in self reflexive ways. They served as a jumping off point to discuss issues of representation and it gave participants something concrete to react to.

\section{Clip: All American Girl: Season 1, Ep. 1 "Pilot"}

Summary: The Cho family are eating dinner and Margaret is arguing with her mother about her boyfriend, Kyle. Margaret's mother disapproves because he's "American." Margaret counters, "Well, I've got news for you mom, I'm American." All American Girl, although panned by critics and audiences, was the first Asian American family on primetime television and offers a glimpse at Asian representation during the mid-1990s. The sitcom premiered in the fall of 1994 and ran for one season. It starred comedian Margaret Cho as a rebellious teenager living with her family in New York. Much of the show's plot lines riffed off the cultural tensions between assimilated Margaret and her "traditional" family. All American Girl was criticized for highlighting American ideals and rejecting Asian values (Halualani \& Vande Berg, 1998) but I've included this clip for context. It was the first of its kind and produced by Disney, which had a history of creating oppressive images of Asians (Halualani \& Vande Berg, 1998).

2. Clip: Fresh Off the Boat: Season 1, Ep. 1 "Pilot"

Summary: A young Taiwanese American boy named Eddie is bullied for bringing Asian food to lunch. Once he opens his lunch, his white classmates voice their disgust 
by yelling, "Ying Ming's eating worms." The next day Eddie brings "white people food" but this time a black student confronts Eddie and says, "Get used to it. You're at the bottom now, chink." The two physically fight. Later, Eddie's parents are called into the principal's office. Eddie's parents defend his actions and question the school's treatment towards their son. They threaten to sue the school if Eddie is suspended. Grinning they explain, "that's the American way."

ABC's Fresh Off the Boat faced enormous pressure to "get it right" after All American Girl failed to represent the Asian American community. The show has been described as revolutionary and ground breaking for its treatment of the Asian American experience but it has also faced criticism for perpetuating racist sitcom troupes, misogyny, and anti-blackness (Chu, 2015). Huang, who the show is based off, has been vocal about his disappointment in $\mathrm{ABC}$ for their interpretation of his life story. Huang described the show as an "entertaining but domesticated vehicle to sell dominant culture" (Huang, 2015, para. 77). He felt the characters were neutered, exoticized, and urbanized to make Asian culture more palatable for white audiences (2015). However, Huang has defended this specific clip. He said racial slurs were an accurate reflection of his experience (Tsai, 2014, para. 2). Overall, Fresh Off the Boat has been positively received with an average of four million viewers per episode (Otterson, 2017, para. 4).

3. Clip: Community: Season 1, Ep. 2 "Spanish 101"

Summary: Señor Chang confronts Asian stereotypes in a classroom full of adults. He explains, "Every once in a while a student will come up to me and ask, Señor Chang, 
why do you teach Spanish? They say it just like that. Why do you teach Spanish? Why. You. Why not math? Why not photography? Why not martial arts? I mean, surely, it must be in my nature to instruct you in something that's ancient and secret, like, oh, building a wall that you can see from outer space! Well, I'll tell you why I teach Spanish. It is none of your business, okay? I don't wanna have any conversations about what a mysterious, inscrutable man I am. I am a Spanish genius!"

Community, a wry, smart comedy with a diverse cast, ran for six seasons before its cancellation in 2015. Critically acclaimed with a strong cult following, Community appeared on a number of 'Best of' lists in 2009, 2010 and 2011. The show's ensemble cast featured an over the top, unstable Spanish teacher named Señor Chang, portrayed by Asian American actor Ken Jeong. Señor Chang provides an interesting jumping off point for discussions because his character has been simultaneously criticized for perpetuating racist stereotypes and praised for challenging them (Chow, 2015; Stewart, 2011).

\section{Clip: Kim's Convenience: Season 1, Ep. 2 "Janet's Photos"}

Summary: Jung Kim approaches his boss, Shannon, to inquire about a promotion. At first she is surprised because of Jung's past in juvenile detention but then takes the opportunity to make sexual advances toward Jung. Shannon comments, "I think you'd do a great job. You've got wonderful people skills, strong physical presence, amazing posture. When I picture someone under me — working under me, that someone looks a lot like you." 
Canada's first East Asian-led sitcom, Kim's Convenience, debuted on CBC in 2016 (Hunt, 2015). The show was adapted from a stage play by Canadian actor and playwright, Ins Choi, and follows the misadventures of a Korean Canadian family who operate a convenience store in Toronto. Recently renewed for a second season, Kim's Convenience has been described as a "charming, effervescent, and modern sitcom" that finally highlights Asian Canadian experiences (Lee, 2016).

\section{Clip: Master of None: Season 1, Ep. 4 "Indians on TV"}

Summary: Dev is accidently copied on an email where a TV producer writes racist comments about having two Indian actors star in an upcoming sitcom. Dev, explaining the situation to his friends, says, "They just don't want two Indian dudes starring in a sitcom. Indians just aren't at that level yet. Yeah, there's more Indian dudes popping up every now and then but we're like set decoration. We're not the ones doing the main stuff. We're not fucking the girls and all that stuff. We're just not there yet. There can be one but there can't be two. Black people just got to there can be two status and even then there can't be three because then it's, like, a black show. Indians, Asians, gays, there can be one but there can't be two.

Netflix's Master of None is created and produced by Aziz Ansari and Alan Yang. Self-aware, humorous, and relatable, the show has achieved critical and commercial success, including a Peabody Award and an Emmy award, while tackling racial barriers traditionally seen on TV.

Each clip explores a specific aspect of identity, such as the tensions between ethnicity and nationality, stereotypes, sexuality, or racial prejudice. Media critics and writers have applauded these shows and their attempts to honestly portray the lived 
experiences of Asian Americans and Canadians. Some of the clips purposely challenge or subvert stereotypes, while others portray the difficult realities of race, but they (with the exception of All American Girl) do not represent a common Asian stereotype. Open-ended, broad questions (see appendix) were projected on a large screen after each clip to help guide and encourage discussions.

\subsection{Recruitment}

Recruitment took place over a two and a half week period at Carleton University and through campus related clubs. The target audience was undergraduate students because research indicates ages eighteen to twenty-four are pivotal years during one's development and understanding of identity (Erikson, 1959). Participants were required to be at least 18 years of age and comfortable talking about racial identity. A limitation from this criteria is that it excludes people who are impacted by representations but feel uncomfortable discussing in group settings. To recruit Asian Canadian participants I contacted a Carleton student club that explores Asian Canadian identity. The club appeared to consist of predominantly Asian undergraduates but they welcome students from all backgrounds. They hold social and educational events throughout the year to raise awareness and build connections in their communities. The club shared the details of the study twice on their Facebook page. ${ }^{3}$ I also attended one of their events, an informal lunch on campus, to recruit participants.

To recruit for the non-Asian session, I put up seventy-five posters (see appendix) on walls and bulletin boards around high traffic areas at Carleton University. There are

\footnotetext{
${ }^{3}$ In January 2017 their Facebook page had 418 'Likes'.
} 
twenty official university bulletin boards located throughout campus that are available to promote university related news, info, and events. The university students association also maintains a number of bulletin boards as well as each faculty, school, institute, or department on campus. The posters may have only attracted those who felt strongly about race, whether it be positively or negatively, which impacted the generalizability of the results. However, given my resources and the size of this project, I felt posters were the best approach because I needed to quickly and cost effectively reach a large group of young adults. Four graduate students also assisted in recruitment by putting up posters, sharing the study's details via social media, ${ }^{4}$ and by word of mouth. I did not disclose my focus on Asian representation because I felt it would narrow my pool of potential participants.

\subsection{Participants}

A total of twenty-seven students contacted me via email about the study. I requested each participant fill out a questionnaire (see appendix) to identify their name, program of study, age, gender, TV preferences, and race and ethnicity. From here prospective participants were split into either the non-Asian group or the Asian group in order to compare and contrast how participants made sense of Asian representations. Each participant was required to sign a consent form and informed that their data could not be kept confidential due to the format but that all identifying information would be stripped in final reports. Participants were told the sessions would be audio and video recorded, transcribed, and emailed to them, at which point they had fourteen days to

\footnotetext{
${ }^{4}$ Study details were shared to a combined audience of over 1,888 Facebook users
} 
withdraw or request their data be removed. Three participants requested parts of their data be removed or altered for clarification.

\subsubsection{Non-Asian Focus Group}

The non-Asian group consisted of eleven university students ranging in age from eighteen to twenty-eight, with the average age being twenty years old. Eight identified as female and three as male. Five participants identified as black, three as white, two as biracial, $^{5}$ and one as South Asian. ${ }^{6}$

Table 1: Non-Asian Focus Group Data

\begin{tabular}{|c|c|c|c|c|c|c|}
\hline Pseudonym & Age & Gender & $\begin{array}{l}\text { Racial } \\
\text { Identity }\end{array}$ & $\begin{array}{l}\text { Racial identity } \\
\text { in their own } \\
\text { words }\end{array}$ & $\begin{array}{l}\text { Hours per } \\
\text { week spent } \\
\text { watching } \\
\text { TV }\end{array}$ & $\begin{array}{l}\text { Type of } \\
\text { programming } \\
\text { typically } \\
\text { watched }\end{array}$ \\
\hline Aamir & 18 & Male & $\begin{array}{l}\text { South } \\
\text { Asian }\end{array}$ & $\begin{array}{l}\text { "South Asian + } \\
\text { Middle Eastern } \\
\text { (Pakistan!)" }\end{array}$ & 10 hours & $\begin{array}{l}\text { "Documentarie } \\
\text { s, comedy } \\
\text { shows, news, } \\
\text { crime dramas" }\end{array}$ \\
\hline Faith & 18 & Female & $\begin{array}{l}\text { Black, } \\
\text { white }\end{array}$ & $\begin{array}{l}\text { "White passing, } \\
\text { half black person } \\
\text { who grew up in } \\
\text { an exclusively } \\
\text { culturally black } \\
\text { environment" }\end{array}$ & 70 hours & $\begin{array}{l}\text { "Sci fi (Star } \\
\text { Trek, Firefly, } \\
\text { X Files) } \\
\text { comedy (Peep } \\
\text { Show, The } \\
\text { Office, Archer, } \\
\text { The Eric } \\
\text { Andre Show, } \\
\text { Tim and Eric, } \\
\text { It's Always } \\
\text { Sunny in } \\
\text { Philadelphia)" }\end{array}$ \\
\hline Kelly & 18 & Female & Black & $\begin{array}{l}\text { "Ghanaian - } \\
\text { Canadian" }\end{array}$ & 3 hours & $\begin{array}{l}\text { "YouTube - } \\
\text { College } \\
\text { Humour, the } \\
\text { Skin Deep" }\end{array}$ \\
\hline
\end{tabular}

\footnotetext{
${ }^{5}$ One participant identified as white and Asian and was presented with both timeslots (but uninformed on how they were organized) and chose to attend the first session due to scheduling conflicts.

${ }^{6}$ I was unaware of this participants ethnic and racial identity and would have preferred to place them in the Asian focus group.
} 


\begin{tabular}{|c|c|c|c|c|c|c|}
\hline Cindy & 19 & Female & Black & $\begin{array}{l}\text { "Nigerian } \\
\text { immigrant } \\
\text { studying in } \\
\text { Canada" }\end{array}$ & $7-14$ hours & $\begin{array}{l}\text { "Drama - } \\
\text { Scandal, } \\
\text { Grey's } \\
\text { Anatomy, How } \\
\text { to Get Away } \\
\text { with Murder, } \\
\text { Jane the Virgin } \\
\text { Pop Culture: } \\
\text { Boondocks, } \\
\text { Family Guy, } \\
\text { Community, } \\
\text { Insecure" }\end{array}$ \\
\hline Kirstin & 20 & Female & White & $\begin{array}{l}\text { "I am born and } \\
\text { raised in Canada" }\end{array}$ & 2 hours & $\begin{array}{l}\text { "Kdramas, } \\
\text { comedy shows } \\
\text { and webseries" }\end{array}$ \\
\hline Rylie & 20 & Female & $\begin{array}{l}\text { White, } \\
\text { Chinese }\end{array}$ & $\begin{array}{l}\text { "I am half- } \\
\text { English and half - } \\
\text { Chinese" }\end{array}$ & 2-3 hours & $\begin{array}{l}\text { "I am typically } \\
\text { into superhero } \\
\text { shows, action } \\
\text { shows, sci- } \\
\text { fi/fantasy, } \\
\text { shows with } \\
\text { critical } \\
\text { acclaim, etc." }\end{array}$ \\
\hline Ada & 20 & Female & Black & $\begin{array}{l}\text { "I am a black } \\
\text { woman from the } \\
\text { Democratic } \\
\text { Republic of the } \\
\text { Congo." }\end{array}$ & 3 hours & $\begin{array}{l}\text { "YouTube } \\
\text { videos, Netflix } \\
\text { shows, } \\
\text { newscasts" }\end{array}$ \\
\hline Katie & 20 & Female & Black & $\begin{array}{l}\text { "Black or } \\
\text { Caribbean" }\end{array}$ & 10 hours & $\begin{array}{l}\text { "Mainly } \\
\text { Netflix or } \\
\text { YouTube or } \\
\text { network } \\
\text { webseries" } \\
\end{array}$ \\
\hline Tom & 21 & Male & White & "Caucasian" & 30 hours & $\begin{array}{l}\text { "Dramas, } \\
\text { comedies, } \\
\text { some news } \\
\text { flash } \\
\text { programs." }\end{array}$ \\
\hline Ruth & 21 & Female & Black & $\begin{array}{l}\text { "Nigerian - } \\
\text { Canadian, Black } \\
\text { Canadian" }\end{array}$ & 5 hours & $\begin{array}{l}\text { "Generally, } \\
\text { political } \\
\text { dramas (like } \\
\text { Madam } \\
\text { Secretary), or } \\
\text { mystery/detecti }\end{array}$ \\
\hline
\end{tabular}




\begin{tabular}{|c|c|c|c|c|c|c|}
\hline & & & & & & $\begin{array}{l}\text { ve dramas (like } \\
\text { Sherlock or } \\
\text { Elementary), } \\
\text { and comedies } \\
\text { (like Blackish } \\
\text { or The Daily } \\
\text { Show)" }\end{array}$ \\
\hline John & 28 & Male & White & $\begin{array}{l}\text { "I would describe } \\
\text { it as White" }\end{array}$ & $\begin{array}{l}15-20 \\
\text { hours }\end{array}$ & $\begin{array}{l}\text { "I watch } \\
\text { educational } \\
\text { videos, } \\
\text { political satire, } \\
\text { comedy } \\
\text { sitcoms, } \\
\text { procedural } \\
\text { dramas, } \\
\text { general news } \\
\text { and } \\
\text { occasionally } \\
\text { movies" }\end{array}$ \\
\hline
\end{tabular}

\subsubsection{Asian Focus Group}

The Asian focus group consisted of six university students ranging in age from twenty to twenty-seven with the average age being twenty-two years old. Four identified as female and two as male. Three participants identified as Chinese, two as South Asian, and one as Filipino.

Table 2: Asian Focus Group Data

\begin{tabular}{|l|l|l|l|l|l|l|}
\hline Pseudonym & Age & Gender & $\begin{array}{l}\text { Racial } \\
\text { Identity }\end{array}$ & $\begin{array}{l}\text { Racial identity in } \\
\text { their own words }\end{array}$ & $\begin{array}{l}\text { Hours per } \\
\text { week spent } \\
\text { watching } \\
\text { TV }\end{array}$ & $\begin{array}{l}\text { Type of } \\
\text { programming } \\
\text { typically } \\
\text { watched }\end{array}$ \\
\hline Claire & 20 & Female & Filipino & $\begin{array}{l}\text { "I would call myself } \\
\text { Filipino-Canadian: } \\
\text { born to Filipino } \\
\text { immigrant parents in } \\
\text { Canada." }\end{array}$ & $\begin{array}{l}20 \text { hours } \\
\text { "I watch light } \\
\text { comedies or } \\
\text { dramedies" }\end{array}$ \\
\hline Sarah & 20 & Female & Chinese & $\begin{array}{l}\text { "CBC - Canadian - } \\
\text { born Chinese" }\end{array}$ & 14 hours & $\begin{array}{l}\text { "YouTube, } \\
\text { Online } \\
\text { streaming" }\end{array}$ \\
\hline
\end{tabular}




\begin{tabular}{|l|l|l|l|l|l|l|}
\hline Sam & 21 & Female & Chinese & $\begin{array}{l}\text { "Chinese } \\
\text { Canadian/Asian" }\end{array}$ & $\begin{array}{l}15 \text { hours } \\
\text { (5 hours } \\
\text { online, 10 } \\
\text { hours TV) }\end{array}$ & $\begin{array}{l}\text { "Comedies - } \\
\text { New Girl, } \\
\text { Modern } \\
\text { Family, etc." }\end{array}$ \\
\hline Amar & 22 & Male & $\begin{array}{l}\text { South } \\
\text { Asian }\end{array}$ & $\begin{array}{l}\text { "Technically I am of- } \\
\text { course, a Punjabi and } \\
\text { there can be no } \\
\text { variance in this as } \\
\text { ethnic/racial identity is } \\
\text { something that every } \\
\text { individual is born into. } \\
\text { However, on a } \\
\text { personal level I do not } \\
\text { feel any level of } \\
\text { affiliation with a } \\
\text { particular group or } \\
\text { culture." }\end{array}$ & $\begin{array}{l}\text { "My range of } \\
\text { media is quite } \\
\text { diverse and } \\
\text { usually } \\
\text { includes but is } \\
\text { not limited to: } \\
\text { films, TV } \\
\text { shows, talk } \\
\text { shows, } \\
\text { documentaries } \\
\text { anime, } \\
\text { cartoons etc." }\end{array}$ \\
\hline Caitlin & 23 & Female & Chinese & $\begin{array}{l}\text { "I define myself as } \\
\text { being the 5th } \\
\text { generation Canadian- } \\
\text { born Chinese person } \\
\text { with influences from } \\
\text { China and Malaysia." }\end{array}$ & 10 hours & $\begin{array}{l}\text { "TV shows I } \\
\text { enjoy: Person } \\
\text { of Interest, } \\
\text { Jane the } \\
\text { Virgin, } \\
\text { Sherlock, } \\
\text { Broadchurch, } \\
\text { Dexter, Black } \\
\text { Mirror, Suits, } \\
\text { Arrow, Flash, } \\
\text { Jessica Jones, } \\
\text { etc." }\end{array}$ \\
\hline Arav & 27 & Male & South & Asian & & $\begin{array}{l}\text { "A lot of } \\
\text { Indian films, } \\
\text { Netflix, TV } \\
\text { shows, } \\
\text { documentaries } \\
\text { "Indian, South Asian, } \\
\text { from the sub - } \\
\text { continent." }\end{array}$ \\
\hline
\end{tabular}




\subsection{Coding/Analysis}

To analyze the data, I used a combination of two approaches: a constant comparison analysis and a thematic analysis. A constant comparison analysis involves attaching codes to raw data. Next, codes are grouped into categories, and then the researcher looks for larger themes (Onwuegbuzie, Dickinson, Leech \& Zoran, 2009, p. 5). This approach is beneficial because I can look for similar themes that emerged during both groups them compare them. The second approach, thematic analysis, is also a way to identify and report themes but is more flexible. It's not tied to a specific theoretical position (Braun \& Clarke, 2006) which suits this study because there is a lack of research in this area. Therefore, having theoretical freedom "can potentially provide a rich and detailed, yet complex, account of data" (Braun \& Clarke, 2006, p. 78). Additionally, this method is well suited to studying people's experiences and their construction of meaning. I used an inductive approach to identify themes. I had my own assumptions as to how participants may react but I didn't try to create codes to fit a pre-existing idea or framework. Throughout the coding process I recoded reflexive comments. Doing so helped me acknowledge that my perspective will influence my research choices. It also enabled me explore perspectives that differed from my own. For example, Amar said racial representations shouldn't affect those with "stable mindsets." Instead of dismissing this idea because it didn't align with my own views, I tried to reflect on why I didn't agree. Investigating this perspective helped explain why some may not feel like representations are problematic and it also led to the exploration of other concepts like media literacy. By recording reflexive comments and observations I was able to 
acknowledge how my point of view has impacted the design, data, and analysis of this thesis.

I familiarized myself with the data by watching the video recordings of both sessions and taking notes. Then I transcribed each session using Microsoft Word. Next, I started coding. I went through the transcripts line by line and tagged sections of text with codes. The initial codes emerged from the transcripts (see appendix C). I used direct words or phrases from participants. For example, one participant commented, "Minorities are not human beings." The code that I tagged this section of text with was "not human". Some codes overlapped and some were contradictory. At the end of the initial coding, I had fifty four codes. The codes and data were entered into an Excel spreadsheet. I did a second scan which yielded seven additional codes. Once satisfied, I started searching for themes among my codes. I eliminated twenty eight repetitive and/or vague codes and then organized the remaining thirty three codes into patterns, which do not necessarily reflect participants' exact words but attempt to see these statements as examples of broader discourses about race, identity, and belonging (see table 3). I created a visual map to identify major themes, sub-themes, and possible links between them. I then reviewed and refined my themes by rereading my data extracts and evaluating whether or not they fit within their designated theme or sub-theme.

\section{Table 3: Sample of Coding}

\begin{tabular}{|l|l|}
\hline Data & Code \\
\hline $\begin{array}{l}\text { "I'm Congolese. My parents are from the } \\
\text { Congo. That's just always how I've seen it." }\end{array}$ & 1. Proud of racial and ethnic heritage \\
"I don't feel like I'm from Ottawa. I've always & 2. Does not identify with Canadian \\
\hline
\end{tabular}




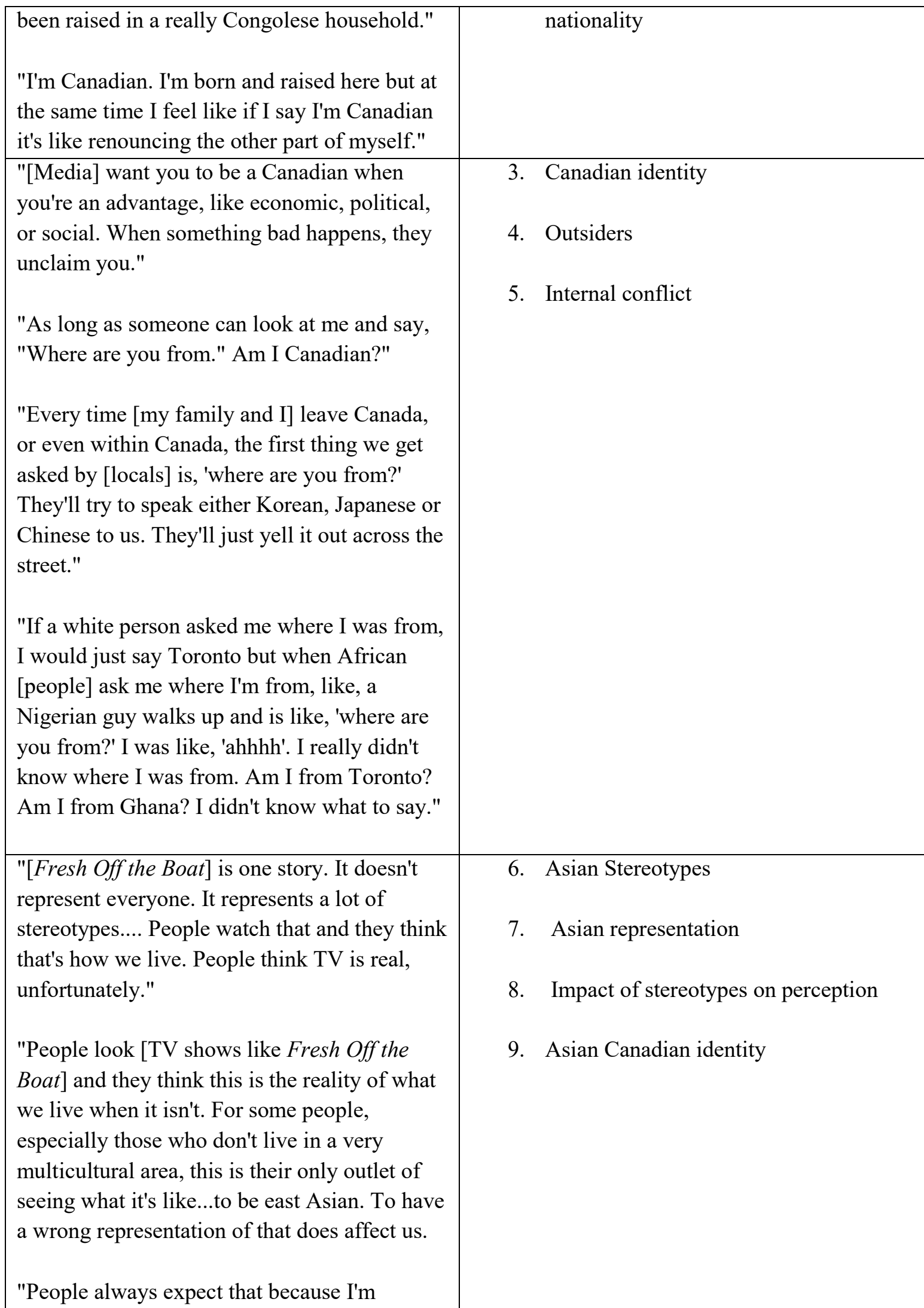




\begin{tabular}{|c|c|}
\hline $\begin{array}{l}\text { Chinese I'm going to be technologically } \\
\text { capable [and] that I'm going to be able to do } \\
\text { these math things... but I'm not. It's frustrating } \\
\text { to be boxed into this because on one hand, you } \\
\text { are expected to excel, so you have these } \\
\text { unrealistically high standards put on you in } \\
\text { this one area. In other areas where you really } \\
\text { do excel, they don't take you seriously because } \\
\text { you're not expected to excel in them... I just } \\
\text { wish that we would be as human and as } \\
\text { individual as white people are." }\end{array}$ & \\
\hline $\begin{array}{l}\text { "In the cinematic universe of Marvel and DC } \\
\text { they've got so many millions riding on it. That } \\
\text { for them to mess up and cast someone too } \\
\text { diverse...even a five percent drop in movie } \\
\text { going happen as a result of that, heads are } \\
\text { going to roll." }\end{array}$ & $\begin{array}{l}\text { 10. Hollywood as a business } \\
\text { 11. The right to a profit } \\
\text { 12. Downplaying the role of media } \\
\text { 13. Individuals shaping their own identity }\end{array}$ \\
\hline $\begin{array}{l}\text { "I think this overemphasis on diversity } \\
\text { ultimately leads us to a point where the } \\
\text { original vision of the artist is being diluted. } \\
\text { This is not just a visual change that had been } \\
\text { done, changing the protagonists race morphs } \\
\text { the whole dynamic he has with other } \\
\text { characters." }\end{array}$ & $\begin{array}{l}\text { s. Individuals shaping their own identity, } \\
\text { separate from media representations }\end{array}$ \\
\hline $\begin{array}{l}\text { "Personally, I really don't like that clip. I } \\
\text { appreciate it for bringing these topics to hand } \\
\text { but it's so uncomfortable to watch that happen } \\
\text { because I've experienced it. It's like reliving } \\
\text { these memories that I really, really, hate..." }\end{array}$ & 14. Negative reaction \\
\hline $\begin{array}{l}\text { "I really like that clip because it really did } \\
\text { resonate with my own experience. Where was } \\
\text { this show when I was a kid?" }\end{array}$ & 15. Positive reaction \\
\hline $\begin{array}{l}\text { "I am a third generation [Canadian] meaning } \\
\text { my grandparents and great- grand parents } \\
\text { immigrated here. My parents are Canadian } \\
\text { born. My experiences are extremely different. } \\
\text { I don't eat Chinese food all the time at home. I } \\
\text { usually eat western food." }\end{array}$ & $\begin{array}{l}\text { 16. Distance oneself from racial/ethnic } \\
\text { background }\end{array}$ \\
\hline $\begin{array}{l}\text { "For a long time when I was little, I really } \\
\text { wanted to distance myself from Chinese } \\
\text { culture because I was born in Ottawa. I was }\end{array}$ & \\
\hline
\end{tabular}




\begin{tabular}{|c|c|}
\hline $\begin{array}{l}\text { raised here. I'm surrounded by the Canadian } \\
\text { culture.... [My parents] never really forced the } \\
\text { Chinese culture on me too much... I really } \\
\text { wanted to fit in...it felt easier to do so if I } \\
\text { called myself Canadian and distanced myself } \\
\text { from being Chinese as opposed to highlighting } \\
\text { that one difference." }\end{array}$ & \\
\hline $\begin{array}{l}\text { "I don't know too much about the Asian } \\
\text { experience, don't know very much about the } \\
\text { black experience, but I'm still part of the } \\
\text { immigrant experience." } \\
\text { "The moment they learn I'm from the states, } \\
\text { they hate me." } \\
\text { "My name is Scottish and [teachers] still fuck } \\
\text { it up." }\end{array}$ & 17. Trying to relate \\
\hline $\begin{array}{l}\text { "Minorities are not human beings. They're just } \\
\text { like these little like, caricature, like you're not } \\
\text { a human you're just a picture." } \\
\text { "This is just my overall opinion on perceptions } \\
\text { of racialized people in general, I just wish that } \\
\text { we would be as human and as individual as } \\
\text { white people are." } \\
\text { "I just want to be seen as a human and an } \\
\text { individual and not have these perceptions put } \\
\text { on us. In media I want to see that reflected, } \\
\text { too. I want us to be treated as just humans" }\end{array}$ & 18. Not human \\
\hline
\end{tabular}

I identified three major themes: the influence of historical stereotypes on making meaning, the role of media in shaping our worldview, and struggles in racial, ethnic, and national identity. These are discussed in the chapters two and three: chapter two addresses the cognitive function of stereotypes, contextualizes the history of widespread Asian stereotypes, and explores how participants reacted to media representations, while 
chapter three discusses how participants made sense of their racial, ethnic, and national identity in the context of Canadian multiculturalism. 


\section{Chapter: Making Sense of Asian American and Canadian}

\section{Representations}

At fifteen per cent of the total population, Asians are the fastest growing and largest ethnic minority in Canada (Statistics Canada, 2011). But when I was a kid seeing an Asian person on TV was rare. They never slayed vampires in Sunnydale, sipped coffee at Central Perk, or broke the fourth wall at Bayside High. My favourite television shows during the late 1990s to early 2000s like Buffy the Vampire Slayer (1997-2003), Friends (1994-2004), and Saved by the Bell (1989-1992) featured no Asian leads or supporting characters. By the late 1990s white characters made up eighty-eight per cent of regular roles in top viewed primetime shows (Tukachinsky, Mastro \& Yarchi, 2015, p. 24).

Decades later, Asian Americans and Canadians are now directing, starring, and producing network TV shows and web series. Can these changes positively influence the way young adults feel about Asian Americans and Canadians? Do past depictions (or the lack thereof) influence the way individuals make sense of current Asian representations?

I expected that most participants, but especially Asian Canadians, would react positively to recent images of Asian Americans and Canadians in mainstream media because the clips selected for this study showed a diverse range of Asian American and Canadian experiences in non-stereotypical ways. Existing scholarship supports this expectation. Greenberg's drench hypothesis (1988) suggests that relatively few "critical images" can potentially offset more common and normalized stereotypes. If images are engaging and unique they may have a greater impact than more common and frequent images (Graves, 1996). For example, the Cosby Show (1984-1992) portrayed Black 
Americans in positive and non-stereotypical ways, which was noticeably different from anything on TV during the time. The show was a critical and commercial success. It challenged the perception of the typical black American family and paved the way for a number of sitcoms during the 1990s with predominantly black casts. More recent studies suggest positive representations can negate stereotypes provided they are diverse and tap into familiar narratives (Tukachinsky, 2015, p. 188). Ramasubramanian's (2015) study found that racial/ethnic attitudes are flexible and that exposure to positive stories about non-white celebrities promoted positive attitudes and feelings about that group. Therefore, I anticipated that positive Asian American and Canadian representations could activate positive attitudes about Asians.

Instead, I was surprised to make two different observations. The first and most apparent was that past depictions influenced how current representations were interpreted. Participants consciously or unconsciously used stereotypes to frame and situate their thoughts and opinions. Some participants felt stereotypes were rooted in truth, others dismissed them as inaccurate and harmful, but most relied on these widespread generalizations to understand media images of Asian Americans and Canadians. Walter Lippman (1922) suggests this is because stereotypes are useful and a necessary part of society. Almost like a road map, common Asian stereotypes gave participants a frame of reference from which they could quickly find meaning. East Asian participants felt isolated and misrepresented by the clips, while non-Asian participants understood the clips in stereotypical ways even when none were present. The second observation was that some participants downplayed the role of media representations altogether. They felt stereotypes were essentially harmless because everyone is subject to 
them. This perspective highlights the media as a tool used by dominant groups to maintain their hegemony and it also illustrates the importance of media literacy. This chapter unpacks how university students made sense of Asian American and Canadian representations. First, I review and contextualize the history of East Asian stereotypes in mainstream media, specifically whose interests they serve and the conditions that led to their creation. Second, I discuss how participants used these stereotypes to understand current representations. The results support the assumption that TV is highly influential and significantly impacts the way we understand the world and our place within it.

\subsection{Stereotypes}

Stereotypes in media are common. They are a cheap and cost effective way to tell a story because they require very little introduction or explanation. Stereotypes can be broadly defined as "characteristics that we apply to others on the basis of their national, ethnic or gender groups" (Schneider, 2004, p. 8). There are three general perspectives to the study of stereotyping: sociocultural, psychodynamic, and cognitive (Ashmore \& Del Boca, 2015). A sociocultural perspective suggests that stereotypes emerge from one's culture and that "the media and other socializing agents directly and effectively teach prevailing cultural stereotypes" (Ashmore \& Del Boca, 2015, p. 25). Stereotypes are assumed to serve "utilitarian and value-expressive functions" in society (Ashmore \& Del Boca, 2015, p. 24). Scholars such as Lippmann (1922) and Katz and Braly (1933) are linked to this perspective. A psychodynamic perspective focuses on one's personality, intergroup relations, and prejudice. This approach suggests stereotyping stems from one's perceived physiological inadequacies. For example, stereotypes may emerge as a defense mechanisms or as a result of displaced aggression. Psychodynamic approaches are rooted 
in Freudian psychology. Lastly, a cognitive approach to stereotyping suggests that cognitive limitations make humans "susceptible to systemic biases in processing information about people and events, and these biases contribute significantly to the formation and maintenance of stereotypes regarding social groups" (Ashmore \& Del Boca, 2015, p. 29). This thesis approaches stereotypes from a sociocultural and psychodynamic perspective because I wanted to explore the link between media, stereotypes, and the way one perceives of themselves.

Lippmann (1922) suggests stereotypes are useful and serve a necessary purpose (p. 60). The majority of us are told about the world before we can experience it. Humans don't have the time, opportunity, or mental stamina to intimately familiarize themselves with each and every thing, person, or place they come in contact with (p. 59-60). Stereotypes provide a necessary shortcut. Individuals "notice a trait which marks a well known type, and fill in the rest of the picture by means of the stereotype we carry about in our heads" (p. 60). Generalizing is a "central, primitive, hardwired cognitive activity" (Schneider, 2004, p. 8). It gives order and comfort to an otherwise chaotic space by condensing or simplifying. Stereotyping allows for a "consistent picture of the world to which our habits, our tastes, our capacities, our comforts and our hopes have adjusted" (Lippmann, 1922, p. 63). Lippmann argues abandoning stereotypes in favour of a more innocent approach "would impoverish human life" (p. 61). They free us but also limit us. The dangers of stereotyping arise when they are false or used to make incorrect judgments about others (Schneider, 2004, p. 21). Stereotyping allowed participants to make meaning or quickly "fill in the rest of the picture" by noticing a trait, like ethnicity, and simplifying what that meant to them. As a cognitive process, stereotyping helped 
participants understand images quickly but Asian stereotypes are connected to racial ideology that serves the interests of dominant social groups. Repeat exposure to negative images can result in "the acceptance of stereotypes as a social reality" (Zhang, 2010, p. 21). To better understand the impact of widespread Asian stereotypes in relation to how participants made meaning, it's important to take a closer look at these pervasive images and the material conditions that led to their creation.

\subsubsection{Forever Foreigners and the Yellow Peril}

Historical accounts place Asians in Canada as early as 1788 (Lai, 2011) but they were never to considered to be a "permanent feature" of the nation ( $\mathrm{Li}, 1998, \mathrm{p} .6)$. Asians have made meaningful contributions to Canadian history and have lived in North America for over a century, but they are still portrayed as foreigners. This perception had little to do with race or culture but instead it came from a history of oppression and social alienation from which Asians have paid a high physical, psychological, and emotional cost (Li, 1998). The first wave of Asian immigration occurred during the 1800s. China was in a state of turmoil, experiencing war, rebellion, revolutions, and invasions during the nineteenth and twentieth centuries. Many Chinese left in search of better opportunities. During the Fraser Valley gold rush of 1858, Chinese workers were recruited for labour-intensive jobs such as mining, digging ditches, and building trails and roads. They were treated like disposable, cheap labour and "tolerated" in times of need so long as they "accepted their menial position and avoided competition with white workers" (Li, 1998, p. 30). When the gold rush ended in 1865, animosity and resentment towards the Chinese grew. The Asian population at the time, roughly 4,300, were 
segregated socially, economically, and politically. They were barred from elections and blamed for taking jobs from white workers (Huang, 2006; Lai, 2011).

The Chinese were recruited again in 1871 to build the Canadian Pacific Railway. During this time, an estimated 17,000 Chinese labourers immigrated to Canada and engaged in dangerous and physically demanding jobs (Huang, 2006). Varying accounts estimate somewhere between 600 and 2,200 Chinese men died due to poor working conditions, starvation, floods, accidents, and disease (Library and Archives Canada, 2009). Once the railway was complete the Canadian government enacted the first of numerous anti-Chinese bills (Li, 1998). The Chinese Immigration Act of 1885 imposed a \$50 head tax on every Chinese immigrant; the tax increased to \$500 in 1903 (Huang, 2006). The Chinese Exclusion Act of 1923 outright banned Chinese immigrants from entering Canada with the exception of merchants, students, and diplomats. Chinese men were unable to bring their families to Canada. The Act was repealed in 1947. Finally, the Immigration Act of 1967 liberalized immigration patterns by focusing on skills and education (Lai, 2011).

Asians faced similar conditions in America. Asian immigration began during the California gold rush of the mid-1800s. During labour shortages, white entrepreneurs saw Asian labourers as a quick solution to their problems (Shim, 1998, p. 397). In 1876, the Chinese made up ninety percent of labourers employed by the Central Pacific Railway (Hamamoto, 1994, p. 48). They contributed greatly to the construction of America's first transcontinental railway that connected California to Utah, but in the "historical photograph that recorded this revolutionary engineering feat...there is not a yellow face to be seen among the assembled men" (Hamamoto, 1994, p. 48). The Chinese were not 
invited. Mounting racial tensions led to the Chinese Exclusion Act of 1882, the first federal law in US history to bar immigration on the basis of race (Ono \& Pham, 2009). Institutional racism prevented the Chinese from assimilating into North American life and so they "responded by retreating into their own ethnic enclaves to avoid competition and hostility" (Li, 1998, p. 7). White labourers, who felt threatened during poor economic periods, tried to blame the Chinese for their problems. They were able to easily do this because there already existed a history of the west trying to portray the east as backwards (Said, 1978). Since the thirteenth century, western nations seeking power, masculinity, and justification for imperialism and colonization have made many attempts, through literature and art, to eroticize and feminize the east (Said, 1978). Also the Chinese were visibly different from the predominantly white society and difference is often feared or equated with inferiority.

The Japanese arrived in Canada during the late 1800s and also faced discrimination and prejudice. By 1914 the Japanese population in Canada was an estimated 10,000 and by the early 1940s the Japanese population rose to 23,000 (Ward, 1982, p. 4). But after the attack on Pearl Harbour in 1941, the Japanese in Canada were deemed a threat to national security (Ward, 1982, p. 14). Through the War Measures Act all Japanese Canadians residing within 160 kilometres of the Pacific coast were forced to leave their homes and relocate to internment camps (Library and Archives Canada, 2016). Over 21,000 thousand, or ninety per cent of the Japanese population in Canada at the time, were relocated (Ward, 1982, p. 14). An estimated seventy-five per cent of those were Canadians citizens. The Canadian government stripped the Japanese of their property and forced them to move east of the Rocky Mountains. 
South Asians arrived in Canada during the early 1900s (Buchignani, 1979). Sikhs looking for work settled in British Columbia but because of the animosity towards Asians coupled with the economic depression (1907-1908), South Asians were denied their political, social, and economic rights (Buchignani, 1979, p. 50). In 1908 the federal government banned South Asian immigration into Canada. This lasted for over sixty years. Like the Chinese and Japanese, South Asians were segregated socially, barred from jobs and equal wages, and denied access to education and public facilities. Legal discrimination of Asians in Canada ended in 1950, but social acceptance has been very slow (Ward, 1982, p. 17). Asians may have legal rights and privileges, but societal norms and media representations indicate that Asians are still perceived as inferior to the dominant group in society.

Constructing Asians this way rationalizes racial exploitation and discrimination (Li, 1998). Asians were imagined as dark, sinister forces threatening to overtake western society. They were perceived to be inherently inferior, uncivilized, and untrustworthy. These images were rooted in medieval fears of Mongolian invasions but they re-emerged during the 1800s (Marchetti, 1995, p. 2). The media soon adopted these attitudes and the image of an alien-like race, unwilling or unable to assimilate, became embedded in Canadian and American consciousness (Li, 1998). Cartoons in popular American magazines portrayed Asians with exaggerated physical features and dialects, mocking and characterizing them as inhuman and animal like (Ono \& Pham, 2009). Penny press newspapers, similar in tone to contemporary tabloids, warned whites to be cautious of the yellow peril. The image of Asians as both foreign and dangerous led to the creation of Chinese villains in media such as the infamous Dr. Fu Manchu (Shim, 1998, p. 387-389). 
The character was inspired by writer Sax Rohmer's fascination but limited contact with Chinatown and the Chinese (Ono \& Pham, 2009). The literary character debuted onscreen in 1929 in The Mysterious Dr. Fu Manchu. Swedish-American actor Warner Oland stared as the title character. Even though the character was portrayed as a powerful threat to the west, Dr. Fu Manchu was emasculated. Over time the character became the archetype for the evil mastermind and inspired countless imitations.

During World War II when America and China were allies, Dr. Fu Manchu disappeared. He was replaced by similar caricatures of the Japanese. After the Japanese attack on Pearl Harbour, the image of the "fanatical Kamikaze" emerged (Shim, 1998, p. 391). Film such as Wake Island (1942), The Purple Heart (1944), and Objective Burma (1945), portrayed the Japanese as a "crazy subhuman race running wild" (Shim, 1998, p. 392). Predominantly white nations that also fought against America, such as Germany and Italy, were not subject to the same treatment. Portrayals of Italian and German Americans were negative, but also sympathetic. They were still depicted as humans, but Asians became animal-like subhumans (Shim, 1998). Fu Manchu reappeared during the 1950s when relations between the US and China were strained. The timing of this character supports the assertion that Asian representations are ideological and created to benefit the dominant groups in society (Shim, 1998; Sun et al., 2015).

\subsubsection{The Model Minority}

During the 1950s Canada began losing its skilled labourers to the United States. From 1954 to 1967, approximately 60,230 professionals immigrated to the US (Li, 2000, p. 7). In an effort to maintain human capital and address growing concerns among minority groups, Canada changed its immigration policy in 1967 to a points system. The 
new policy prioritized education and skills over one's country of origin. In the five years after this change, immigration from "previously non-preferred regions" such as China and Africa began to rise, while immigration from Europe decreased (Puplampu \& Tettey, 2005, p. 26). From 1968 to 1995, 4.4 million individuals immigrated to Canada. Thirtynine per cent were from Asia (Li, 2000, p. 6). Elsewhere during the 1950s, the Cold War was ongoing, the civil rights movement was gaining traction, and America was making significant changes to its immigration policies. The US abolished their quota system and adopted a new immigration policy that favoured skills and family ties to US citizens. The US Immigration and Naturalization Act of 1965 declared that no potential immigrant shall be discriminated against because of their "race, sex, nationality place of birth or place of residence" (Immigration and Naturalization Act, 1965).

During this period, the seemingly "positive" model minority myth emerged and the public image of Asians dramatically shifted from threatening to model citizens. "Positive" stereotypes are often treated as harmless but studies show they insidiously promote "antiquated and prejudicial social beliefs" (Kay, Day, Zanna, and Nussbaum, 2012, p. 291). The model minority characterized Asians as good, quiet, successful, and intelligent individuals. It emphasized success through hard work and determination without government assistance $(\mathrm{Wu}, 2003)$. The model minority myth is problematic for three major reasons. First, it masks racism against Asians by exaggerating their economic and academic success. Second, it erases cultural differences among Asians and forces them to live up to a rigid set of standards. Asians are not free to be normal or average. Asians are assumed to be "super geeks" or "genius workaholics" (Wu, 2003, p.76). These expectations are debilitating personally and professionally. Third, it drives "a 
political wedge between racially disadvantaged groups" (Ono \& Pham, 2009, p. 81). The myth undermines "legitimate struggles, activism and legislation for social justice" (Ono \& Pham, 2009, p. 81). The Civil Rights movement sought to end racial segregation and gain equal rights for African Americans but the model minority myth was used to deny African American rights by insinuating that racism can be overcome if you work hard (Chow, 2017, para. 3). Wu (2013) suggests this stereotype was initially created by Asians as a strategy to achieve equality but was then co-opted by dominant groups in society to advance their own agendas. Political leaders in America embraced the model minority stereotype to win allies during the Cold War and to show they were capable of being a world leader (Wu, 2013). America was trying to portray a sense of racial democracy and the surge of Asians immigrating to North America with training and education supported the myth.

\subsubsection{Hypersexualized Women and Asexual Men}

Asian men and women have been imagined very differently in media. Asian men are often asexualized or emasculated. The history of Chinese immigration helped shape this stereotype. Because Chinese men were only allowed to work menial jobs, for example, in restaurants and laundries, they were perceived as doing "women's work" and as a result feminized in media. They also were prohibited from bringing their wives to North America due to laws like the Chinese Immigration Act and the Chinese Exclusion Act. Chinese labourers were forced to develop "bachelor societies." The asexual and nerd stereotype can be seen in American author Earl Derr Bigger's fictional detective Charlie Chan, Long Duk Dong from Sixteen Candles (1984), and Mr. Yunioshi from Breakfast at Tiffany's (1961). Charlie Chan first appeared in 1925 in The House Without a Key. The 
character went on to appear in over forty American films. Chan was non-threatening, unassertive, "effeminate and asexual in his walk and gestures" (Shim, 1998, p. 390). Long Duk Dong from Sixteen Candles was also non-threatening. He spoke with a thick accent, was socially inept, and didn't understand American social norms. His love interest was a teenage girl named Lumberjack. Lumberjack is masculine and physically bigger and stronger than Dong. Their gender roles are switched but at Dong's expense because his femininity is portrayed as a weakness (Ono \& Pham, 2009). Finally, Mr. Yunioshi, portrayed by Mickey Rooney in yellowface, was over the top man with glasses, buck teeth, and a thick "Asian" accent. This stereotype seems to be the opposite of the threatening yellow peril but both portray Asian men as sexually deviant.

Asian women, by contrast, are often hyper-sexualized in mainstream media. The China Doll or Madame Butterfly stereotype portrays Asian women as "alluring and demure, passive, obedient, physically non-imposing, self-sacrificial, and supplicant (especially to white male suitors)" (p. 66). Once they've satisfied the sexual desires of white men, they exit - often by suicide, as seen in Madame Butterfly (1915), Sayonara (1957) and Miss Saigon (1989) (Shim, 1998, p. 389). In contrast to the China Doll is the Dragon Lady. The Dragon Lady stereotype is a "feminized version of the yellow peril" (Ono \& Pham, 2009, p. 66). Manipulative, untrustworthy, and conniving, dragon ladies often use sex or their sexuality to gain control and power. Ono and Pham (2009) suggest the differences between Asian men and women in media stem from colonialism. Establishing Asian women as sexually available and Asian men as asexual or villainous allowed for white men to engage romantically with Asian women (p. 64). The 
relationship is justified because Asian women need to be "saved" from inferior and "barbaric" Asian men (p. 64).

Stereotypes were created or co-opted by predominantly white groups in order to gain control or to justify social, cultural, or legal oppression. The media operate as a tool for the dominant class to maintain their cultural hegemony ${ }^{7}$ (Boggs, 1976; Henry \& Tator, 1999; Lull, 1995). Hegemony can be described as the social process by which one group gains and maintains dominance over another (Lull, 1995, p. 33). Leadership is gained through consent, and consent is obtained by diffusing and popularizing the dominant group's world view (Bates, 1975, p. 352). The dominant group use powerful social institutions like the media, schools, businesses, religious groups, and political organizations to promote their own culture, philosophy, and morals as natural and inevitable rendering social, political, and economic conditions invisible. They use ideological influence to gain social power as ideas favouring the dominant group "become self evident cultural assumptions" (Lull, 1995, p. 33-34). This structure forms a "social bloc" powerful enough to "mute" the struggles of different social groups and allow for "class societies to function" (Bates, 1975, p. 351). Subordinate groups consent to this dominance because they believe the principles, rules, and laws that control them operate in their best interest (Lull, 1995, p. 34). But groups may also resist or challenge dominant ideologies and cultural assumptions.

\footnotetext{
${ }^{7}$ Cultural hegemony is closely associated with the work of Antonio Gramsci, who wrote about the concept while serving a twenty year sentence in prison (Bates, 1975, p.351). Gramsci died in 1935, eleven years after his arrest. His work on hegemony "lies fragmented and dispersed" among his prison notes but scholars after him have expanded his framework (Bates, 1975, p.351).
} 
Mass media support hegemonic ideals of white supremacy by negatively depicting ethnic minorities. And because these messages are constructed as "natural" ethnic minorities may internalize and embrace these narratives. Subordinate groups or subordinate individuals in positions of power may also reinforce hegemonic ideals in exchange for "acceptance" in mainstream society. For example, an Asian American screenwriter may be aware of stereotypes but still reproduce negative images because of perceived notions of what it takes to be successful. Participants in this study adopted widespread stereotypes to make sense of non-stereotypical images of Asians Americans and Canadians.

\subsection{Participant Reactions}

For decades, most Asian characters in mainstream media have embodied some kind of stereotype. There have been exceptions and TV is more diverse now but stereotypes are relatively stable and hard to change. In this study stereotypes influenced the way most university students made sense of Asian representations. Most non-Asian participants were able to easily identify widespread Asian stereotypes. For example, participants described Asians as model minorities and foreigners. One participant noted Asian men are "not supposed to be good looking." Another participant said that Asians are unfortunately forced to "own" any and all misconceptions that North Americans may have of them. They didn't acknowledge social, political, or economic conditions, instead one participant summarized Asians as "another racialized group that people don't really think about."

By contrast, Caitlin, Sam, and Sarah, who were the most outspoken members of the Asian focus group, said they had been negatively impacted by the presence of 
stereotypes in media. They said the clips did not reflect their experiences because they reinforced stereotypes. When they started to discuss with one another it became clear that they did relate to the clips, but they still rejected them. They distanced themselves from media images of Asian Americans and Canadians, even when they were nonstereotypical. For example, when discussing Fresh Off the Boat Sarah ("CBC - Canadian - born Chinese") and Sam ("Chinese Canadian/Asian") initially explain how they did not feel accurately represented:

Sam: [Fresh Off the Boat] is one story. It doesn't represent everyone. It represents a lot of stereotypes... People think TV is real, unfortunately.

Sarah: People look [at TV shows like Fresh Off the Boat] and they think this is the reality of what we live when it isn't. For some people, especially those who don't live in a very multicultural area, this is their only outlet of seeing what it's like...to be East Asian. To have a wrong representation of that does affect us.

People always expect that because I'm Chinese I'm going to be technologically capable [and] that I'm going to be able to do these math things... but I'm not. It's frustrating to be boxed into this because on one hand you are expected to excel, so you have these unrealistically high standards put on you in this one area. In other areas where you really do excel, they don't take you seriously because you're not expected to excel in them... I just wish that we would be as human and as individual as white people are.

Initially, Sam and Sarah said Fresh Off the Boat didn't represent them and it led to preconceived notions of what an Asian person ought to be like. They wanted equality, and Fresh Off the Boat, while making Asian people more visible, wasn't helping achieve that. But then they explained that their rejection of Fresh Off the Boat was due to reliving painful memories:

Sam: To be honest, I saw that clip once before when I tried to watch Fresh Off the Boat but it was too cringe worthy for me, so I stopped. But, I don't know. For me personally watching that clip again, it's kind of sad. Each time I watch it I think it's kind of a sad clip. I actually didn't experience that myself but my parents, like, 
my mom said this happened to her. She was bullied in school. That makes me think I feel sad about their experiences.

Sarah: Personally, I really don't like that clip. I appreciate it for bringing these topics to hand but it's so uncomfortable to watch that happen because I've experienced it. It's like reliving these memories that I really, really, hate...

Sam and Sarah said they felt "uncomfortable" and "sad" in seeing their own or their family's experiences reflected. In an interview with The Wrap Constance $\mathrm{Wu}$, who portrays Eddie's mother, felt the show let minorities reclaim their identity and "celebrate [their] voices" because differences were embraced instead of ridiculed (Appelo, 2015, para. 2). But for Sam and Sarah an Asian American boy bullied and called a racial slur was an experience they didn't want to see reflected. They didn't feel empowered or find comfort in seeing their experiences onscreen. For them it reinforced stereotypical assumptions people have about Asians and showed how prejudice can lead to discrimination and bullying. Sam acknowledged that she appreciated that these issues being brought to light but she was "not comfortable with it because it [brought] up too many of [her] own memories." Interestingly, Huang defended the use of the racial slur in an interview with TIME magazine because it was true to his experiences (Tsai, 2014, para. 2). By comparison the non-Asian focus group also related to being bullied because of their ethnic and racial differences, but they reacted positively. They took comfort in knowing others go through similar experiences whether they are Asian, black, white, or biracial. They even joked with one another about how North American foods like cheese can appear foreign and "disgusting."

Another interesting comparison was the way participants understood Kim's Convenience. The clip purposefully attempts to subvert the asexual male nerd stereotype. 
In an interview with Maclean's magazine, Ins Choi, the creator of Kim's Convenience and co-writer of this particular episode, said it was a "conscious choice" to have a white woman sexually objectify the troubled Asian "heartthrob" because of the history of emasculating stereotypes for Asian men (Lee, 2016, para. 11). Caitlin, Sam, and Sarah were happy to see an Asian male be portrayed as sexually attractive but ultimately felt the character reinforced notions of white superiority and fetishized Asians:

Sam: [Jung is] the complete opposite of what we usually see in the media. The male Asian is usually, like, emasculated and seen as asexual. In this case, this woman is hitting on this Asian man, so it's completely different.

Caitlin: My one problem with the clip is the boss is a crazy cat lady. She can't just be a normal, sexy female that just likes another sexy, Asian guy.

Sarah: There's so much fetishization of racial minorities and especially as an Asian woman, I see a lot of white men who go, "Oh, I want an Asian wife because they are all docile"... I kind of got that vibe from this as well. The whole it's a nice, sexy, Asian man, you know, as opposed to just another man, who happens to be Asian.

In both instances, Fresh Off the Boat and Kim's Convenience, East Asian participants suggested that media representations of Asian Americans and Canadians - even those produced by Asian creatives - reinforce Asians as inferior. Caitlin felt the clip showed that Asian men are subservient to white men because the woman hitting on the Asian character is an outcast. Caitlin suggested that society views it as implausible for a "normal" white woman to find a Asian male attractive, so instead she must be different in order for the scene to be believable.

John ("white") described Jung from Kim Convenience as a "well dressed" and "well mannered" Asian man being "used" by a white woman. Ada ("black") agreed and said Shannon (Jung's boss) "wasn't paying attention to him. He's here for something to 
know if he got the job or not...she's not paying attention to the person in front of her at all." Their description is consistent with the asexual nerd stereotype, even though the clip was actively trying to dismantle that. John also had a similar reaction to Señor Chang from the Community clip:

You visualize what [an Asian Spanish teacher] must have experienced. None of those experiences fit him going to university to learn Spanish. He's Asian, why would he have an interest in Spanish? And so, like, him bringing it upfront from the get-go like, "You don't know me. You don't know anything about me....You don't have any right to judge whether or not I'm qualified. The fact that I am here in front of you should be qualifying enough." But yet, if it was a white person you immediately imagine some sort of like framed, signed, stamped piece of paper but for a minority, you're, like, "How long ago did he move to this country and is he really qualified?"

The way John described characters from Kim's Convenience and Community was consistent with two stereotypes: the nerd and the forever foreigner. John used his existing knowledge of Asians to "fill in the rest of the picture." He said nerds are what he's used to seeing on TV and therefore anything different comes across as a "shock." John explained he is not exposed, through media or his daily life, to different kinds of Asian individuals. Communities are becoming more diverse but individuals still tend to socialize with people of the same racial and ethnic group (Mastro, 2015, p. 2). His candid remarks illustrate how in the absence of direct contact or limited contact, the media act as a substitute - a way to teach society about various groups of people (Mastro, 2015). Repeated exposure to images of Asians nerds has cultivated his social reality. His attitudes, beliefs, and opinions about Asian Americans and Canadians stem from stereotypes. He understood what both scenes were trying to communicate, but Jung is still a nerd and Señor Chang is still a foreigner. 


\subsection{Downplaying Asian American and Canadian Representations}

Individuals possess a "high degree of literacy" when reading media messages (Lewis \& Jhally, 1998, p. 3). They are exposed to and able to make sense of many messages from mass media every single day. The data from this study highlighted two important criteria when making sense of images: the degree of (1) comprehension and (2) awareness. Even though participants could easily make sense of media images their comments suggested that their level of comprehension and awareness was lacking. It's important to know why certain images are produced, by whom, and under what conditions in order to minimize the potentially negative effects of media representations (Lewis \& Jhally, 1998). Amar and John dismissed representations of Asian Americans and Canadians as insignificant. First, they explained media are a business and therefore entitled to make a profit, even if it meant stereotyping groups. Second, they considered media a form creative expression that shouldn't be censored. They also reasoned that everybody is stereotyped, so if you are offended you're simply "taking it too personally." Third, some felt individuals are responsible and in control of their own perceptions and identity. These assertions overlooked the power and influence of media by separating racial ideology from media production, content, and consumption. Participants accepted media as is, some because they didn't feel representations were problematic and others because they disregarded the media's connection to culture and society.

Some participants accepted negative media representations as is. They didn't discuss barriers or alternatives, instead it was described as a part of life. They felt the economy, creative freedom, and individualism took precedence over fair and equal 
representations. For example, John reasoned it was too risky to disrupt the current media system:

Of course, [media executives are] going to go the safe route. And say, "Hey, at the end of the day I'm responsible to my shareholders. I'm going to go the safe route that's going to make me as much money as possible." So, like, in the cinematic universe of Marvel and DC, they've got so many millions riding on it that for them to mess up and cast someone too diverse...even [if] a five per cent drop in movie [attendance] happens ...heads are going to roll.

What's interesting is the way non-white actors are considered "too diverse" or "risky."

Diversity is often constructed as a strength in Canada, but these "diverse" images are embraced only when they reinforce the dominant culture, otherwise they are perceived as "too" much. Initially, TV producers thought portraying sympathetic images of ethnic minorities would alienate the majority. Content was largely motivated by profits (MacDonald, 1992; Tukachinsky, 2015). But industry trends have shifted and so has society. Statistics show that diversity sells. Films with diverse casts "enjoy the highest median global box office receipts and the highest median return on investment" (Hunt, Ramon, Tran, Sargent, \& Diaz, 2017, p. 2). But there still exists this notion that nonwhites are a financial liability or are "too diverse."

Amar ("technically Punjabi" but noted no "level of affiliation with a particular group or culture") felt TV and racial politics were two separate realms:

I think this overemphasis on diversity ultimately leads us to a point where the original vision of the artist is being diluted. This is not just a visual change that had been done, changing the protagonist's race morphs the whole dynamic he has with other characters. You understand? In the Fantastic Four movie that recently came out Johnny Storm [is] black even though in the original he is white. In the new Spider-man Mary Jane is being played by an African American actor even though she's a very iconic redhead in the comic books. Don't you guys think this is a bit weird? This doesn't have anything to do with whether or not a specific cultural group is being represented. All the movies have to do is represent the vision of the authors, of the original source material, right? 
Amar reasoned that changing the race of an iconic character radically changes the storyline and that if a character was white in the original material, they should remain white in any and all retellings. But Johnny Storm and Mary Jane's ethnic and racial backgrounds are not significant to their storylines. Amar felt "smart" audiences of "a stable mindset" understand that representations are born out of "logic" as opposed to "any hidden racism." That is, it's logical to see stereotypical representations or a lack of Asian American and Canadian representations in the media because it's a reflection of reality.

He felt Hollywood should not have to bear the responsibility of reflecting its audience: Instead of relying on Hollywood to someday be gracious enough to let Asians into their movies, why don't the Koreans have their own media? I don't think I've ever heard a white guy say that he or she is not being represented enough in Korean or Bollywood cinema, or even Chinese cinema. Why does Hollywood have to be held accountable for representing all the various nations of the world?

These arguments deny the influence of media and undermine the struggles of racialized groups that continue to be at a social, economic, and political disadvantage. Amar equates America and Hollywood with whiteness and denies the existence of Asian Americans as "real" Americans, which reinforces the perpetual foreigner stereotype. Amar's response may have been prompted by other factors, such as playing the role of devil's advocate, but his comments show a lack of awareness and comprehension of media images. Amar doesn't comment on power relations nor the wider implication of negative representations, instead he felt individuals bothered or upset by Asian American and Canadian representations are "taking it too personally." Hammer (2009) suggests individuals rarely question ideas from those in positions of power or look for progressive alternatives because the current education system "treats students as passive objects of 
indoctrination" (p. 167). She argues "commercial values and market logic supersede fundamental democratic principles of education" such as the ability to be self-reflexive (p. 168). Sun et al.'s (2015) study presented similar findings. They found those without media literacy skills are more likely to accept media representations as the way things are (2015, p. 310).

Arav ("Indian, South Asian from the sub continent") sympathized with those who felt alienated, but also suggested individuals have the power to determine their own identity:

In today's globalized society [we] have full agency to embody any identity that we feel like. I find [stereotypical representations to be] humorous, witty, and ignorant. I don't find it offensive... It doesn't make me go, "I'm offended" or all of a sudden I feel insecure about my identity in a certain cultural, or political, or social space. No, it makes me realize where I come from, what I bring to the table, what that involves.... I love the conversations and full power to people to reclaim their identity in this western space, but it doesn't offend me...It doesn't matter to me because I feel like there's more cultural depth, richness, and content that can co-exist with such racial slurs and it makes me proud of my culture, really, it does.

Arav's attitude, while positive, also downplays the significance of stereotypical representations in mainstream media. There may be other options or ways to find positive images of Asians, like the internet or ethnic media, but these alternatives don't address bigger issues like cultural hegemony and they rely on an individual's willingness to seek out alternatives. Additionally, these representations may go unnoticed by mainstream society. 
These reactions suggest greater need for media literacy education. Media literacy is broadly defined ${ }^{8}$ as "the ability to access, analyze, evaluate, and create messages in a variety of forms" (Aufderheide, 1993, p. 6). Scholars have approached the concept in a number of different ways, which has led to a number of conflicts and debates ${ }^{9}$ within the field. For example, how to distinguish between literacy and activism, the importance of production skills in media literacy education, and whether to adopt a contextual or text based approach (Hobbs \& Jensen, 2009; Lewis \& Jhally, 1998; Scharrer \& Ramasubramanian, 2015). Existing studies on media literacy interventions and education have focused on violence (Tobin, 2000), body image (Yamamiya, Cash, Melnyk, Posavac \& Posavac, 2005), and advertising (Merskin, 2004). Very few studies explore racial stereotyping. Tukachinsky (2015) suggests that media literacy and social awareness are "key" to improving media images of ethnic minorities (p. 195). Scharrer and Ramasubramanian's (2015) study found that media literacy is effective in shifting attitudes but most effective when "used in conjunction with message centered approaches such as exposure to counterstereotypic media exemplars" (2015, p. 176). Participants were able to easily read media messages, but displayed a lack of awareness and knowledge as to why certain images are produced, by whom, and under what conditions.

Historically, Asians had little control and influence over media institutions, so their image in media was based on the dominant society's perception of them (Ono \&

\footnotetext{
${ }^{8}$ This definition originated at the 1992 National Leadership Conference on Media Literacy.

9 Its history is also greatly debated (Hobbs \& Jensen, 2009, p.2). Some say it originated in 5th century B.C. "as an extension of the practice of rhetoric," which taught politics through critical thinking and oratory (Hobbs \& Jensen, 2009, p. 2), while others see the emergence of media literacy as a movement that developed alongside film.
} 
Pham, 2009; Tukachinsky, 2015). These images have come to define Asians and Asian Americans and Canadians to the broader society and to themselves (Hamamoto, 1992; Ono \& Pham, 2009). Existing studies indicate that non-stereotypical images of out groups can be used to promote positive attitudes and reduce prejudice (Ramasubramanian, 2015). I anticipated that participants would react positively to more recent and diverse representations of Asian Americans and Canadians. Instead, I found that stereotypes guided the way participants talked about and made sense of media images indicating a greater need for determining under what conditions prejudice reduction practices are effective, and with which ethnic and racial groups. The findings also suggest that stereotyping may play a larger role when making sense of representations. Stereotyping as a cognitive function helps people make sense of images quickly but Asian stereotypes are rooted in struggles of power and dominance. They were created as a way for the dominant groups in society to maintain their power and justify their oppressive actions. Repeat exposure to these stereotypes makes them "highly automatic" to the point where there is little cognitive activity involved (Zhang, 2010, p. 22). Non-Asian students saw Asian characters and "filled the rest of the picture" with familiar stereotypes even when none were present, and some participants downplayed the effects of media altogether indicating a greater need for media literacy. East Asian participants didn't want to be associated with Asian representations in mainstream media, even if they were nonstereotypical, nor did they want to be reminded of the struggles that Asians have faced. They wanted diverse representations without confronting the hardships Asians have endured, like being bullied (Fresh Off the Boat), doubted because of your race (Community), or denied a job because you're not white (Master of None). They serve as 
reminders that little has changed in terms of the way Asians are treated and perceived by society. The shows are progressive, they increase awareness, and push boundaries by talking about the realities of race, but they also reflect how little progress has been made. These reactions are consistent with the assumption that TV is influential and significantly impacts the way we make sense of ourselves and those around us. The next chapter discusses how representations of ethnic and racial identity in mainstream media impact the identity of Canadian university students. 


\section{Chapter: Identity}

If someone asks, "where are you from?" perhaps they're trying to be polite, respectful, or culturally sensitive by showing an interest in your background, but for Asian Americans and Canadians this question serves as a reminder that you don't quite belong (Ash, 2004; Cheryan \& Monin, 2005; Wu, 2002). Because of the forever foreigner stereotype and identifiable physical differences, Asian Americans and Canadians are "particularly susceptible" to being viewed as outsiders (Cheryan \& Monin, 2005, p. 717). When groups realize that their ethnicity and race are devalued in media and society they may potentially react in one of three ways: (1) they internalize negative messages and believe that they are "bad" by virtue of their racial or ethnic heritage (Huntemann \& Morgan, 2001, p. 317); (2) they attempt to blend in with the dominant culture and distance themselves from their racial or ethnic group (Cheryan \& Monin, 2005; Kim, 2012; Phinney, 1989; Smith, 1991); or (3) they reject negative messages and identify more strongly with their own ethnic and racial group (Huntemann \& Morgan, 2001; Tuan, 1998). The data from this study indicated that several participants struggled with understanding their racial, ethnic, and national identity. They felt Canada's relationship to multiculturalism offered a superficial sense of belonging. But interestingly, most black participants said they didn't care. They displayed signs of ethnic and racial pride and a stronger desire to identify with their African or Caribbean heritage. East Asian participants displayed signs of internal conflict and behaviours consistent with identity denial (Cheryan \& Monin, 2005) and Asian American racial identity development theory (AARID) (see section 4.4) (Kim, 2002). 
This chapter explores the psychological impact of media representations on identity formation in the context of Canadian multiculturalism. First, I contextualize Canada's history as a multicultural nation, then I explore how Canadian identity is constructed in the media and by the participants, followed by a detailed look at how Black and Asian participants made sense of their racial, ethnic, and national identities.

\subsection{Identity and Canadian Multiculturalism}

The way you perceive yourself, the way others see you, and the stories that are told about people like you contribute to your sense of identity. There exists a lot of literature on identity and identify formation. A few noteworthy or prominent scholars and theories include Erikson's theory of psychosocial development (1968), Marcia's identity status theory (1966), and Phinney's model of ethnic identity development (1989).

Erickson's work has greatly influenced the field of psychology and the role of identity formation is present in both his, Marcia's, and Phinney's developmental theories. For the purpose of this thesis, I used Huntemann and Morgan's (2001) understanding of identity because they address the role of mass media and TV in identity formation.

Erikson, a psychologist and psychoanalyst, viewed adolescence is a key period for identity development. He identified eight stages of psychosocial "crises" or "conflicts" that individuals experience over the course of their lifetime. These developmental stages arise when one's psychological needs conflict with societal needs. According to Erikson's theory, between adolescence and young adulthood individuals may face two crises: (1) identity versus role confusion, which is a period of struggle between individual identity and group membership, and (2) intimacy verses isolation, which is a period of exploring close relationships outside of the family. If stages are resolved individuals develop a 
healthy understanding of themselves and can confidently interact with various groups of people without losing their identity. If stages remain unresolved individuals may not have a clear understanding of who they are and they cannot progress to further stages of development (1968).

Marcia's identity status theory expands on Erikson's idea of crises. Marcia identifies four statuses of identity: identity diffusion (unresolved conflicts), identity foreclosure (conforming to values or norms), identity moratorium (periods of exploration), and identity achievement (commitment to identity after exploration). Marcia argues that there are two components to adolescent development: crises and commitment. Crises can be seen as a period of uncertainty, searching, or reevaluation, while commitment is the outcome. It's whether an individual has made a decision or "committed" to a role or identity (1966). From this perspective the decisions we make contribute significantly to the ways we identify.

Phinney's research incorporates both Erickson and Marcia's work on identity formation, but Phinney sought to develop a model that could be applied to various ethnic groups $(1989$, p. 36). Phinney argues that various ethnic groups face similar experiences as they navigate with finding membership in predominantly white societies (p. 45). Her theory identifies three stages of minority identity development: (1) diffusion/foreclosure, (2) moratorium, and (3) achieved.

Finally, Huntemann and Morgan (2001) describe identity as one's own "subjective personhood" (p. 305). They suggest that identity is not fixed or internal but rather a fluid socio-cultural process that is constantly negotiated (p. 305). The media's relationship to identity formation is built on repetitive images. Audiences are active and not likely to be 
directly influenced by a particular image or message, with the exception of a few "critical images" (Greenberg, 1988), but the same kinds of images over and over can shape one's perception, values, and beliefs (Comstock, 1993; Gerbner et al., 2012). Canadian identity offers a paradoxical space of belonging and not belonging (Bannerji, 2000). Under official multiculturalism citizens are encouraged to retain and celebrate their ethnic heritages, but the lack of diverse representations in Canadian media has "effectively decreased the ability for minorities to be seen as positive contributors to Canadian society" (Mahtani, 2001, p. 108). Where did these opposing views come from and how do they impact the way Canadian university students identify?

Canada's reputation as a "tolerant" and multicultural nation emerged as a convenient way to highlight Canada's inclusiveness while ignoring its injustices (Mackey, 2002). Prior to the arrival of European settlers in the fifteenth century, Canada was inhabited by the indigenous peoples. European colonization had devastating effects on the Indigenous population. They were viewed as "uncivilized heathens" by the Europeans and forced to assimilate into Euro-Canadian culture first through religious conversion and then later through formal education (Kirmayer, Simpson \& Cargo, 2003). Their religious beliefs and cultural practices were suppressed by the Canadian government, who surveilled and controlled their lives through federal policies, such as the Indian Act (1876). Cultural oppression and forced assimilation has led to an disproportionately high distribution of mental health and social problems for Aboriginal peoples in Canada (Kirmayer, Simpson \& Cargo, 2003, p. 18). Historic accounts suggest that European settlers were "respectful" of the locals, but explorers depended on the indigenous people's knowledge, corporation, and labour to establish the fur trade (Mackey, 2002). As the 
Aboriginal population collapsed, Britain and France became the primary source of immigrants and over time Canadian culture became a reflection of Western European values, religion, and language.

Much later during the mid-twentieth century Canada entered a period of political stability and the nation was "eager to keep up with global changes to eliminate discriminatory laws" (Puplampu \& Tettey, 2005, p. 26). Over the next few decades, the Canadian government adopted new policies and quietly changed existing acts to underscore the nation's reputation as a peaceful and diverse country. By 1961, Canada's population was forty-three per cent British, thirty per cent French, and twenty-two per cent "other European" (Li, 2000, p. 2). In 1963 the Royal Commission on Bilingualism and Biculturalism was established to develop an equal partnership between Canada's "founding peoples", which at this time was considered to be the British and the French but has since expanded to include Aboriginal peoples (Laurendeau \& Dunton, 1967, p. 91). The commission was a response to French Canadians who felt underrepresented politically and economically. They also felt their culture and language needed to be protected. The commission's recommendations led to the Official Languages Act (1969), which recognized English and French as the two official languages of Canada. In 1967 immigration to Canada was liberalized and by 1971 Canada became the first country to adopt multiculturalism as an official policy. In 1982 the Canadian Charter of Rights and Freedoms was enacted. Section 15 declared every individual "as equal before and under the law...without discrimination based on race, national or ethnic origin, colour, religion, sex, age, or mental or physical disability" (Canadian Charter of Rights and Freedoms, 1982). In 1988, the Canadian Multiculturalism Act was passed. Section three of the act 
recognizes and promotes "the understanding that multiculturalism is a fundamental characteristic of the Canadian heritage and identity and that it provides an invaluable resource in the shaping of Canada's future" (The Multiculturalism Act, 1988).

But multiculturalism in Canada has "largely failed" to achieve equality because "racism and notions of racial superiority are deeply embedded in the collective belief system and in the norms and practices of Canadian society" (Henry \& Tator, 1999, p. 90). Mackey explains that multiculturalism "implicitly constructs the idea of a core EnglishCanadian culture" and everyone else becomes "multicultural" in relation to the "unmarked, yet dominant, Anglo-Canadian core culture" (1999, p. 15). Bhabha (1990), Itwaru and Ksonzek (1994), Wallace (1994), and Henry and Tator (1999) suggest multiculturalism manages cultural diversity and difference by giving the illusion of tolerance and equality. The dominant group sets the standards by acknowledging "these

other cultures are fine but we must be able to locate them within our own grid" (Bhabha, 1990, p. 208). Moreover, celebrating diversity neutralizes "cultural, political, economic and social demands of minorities for access and equity within all sectors of Canadian society" while "preserving cultural hegemony" (Henry \& Tator, 1999, p. 96).

\subsection{Canadian Identity in Media}

In Canada the relationship between identity formation and media is "particularly fraught" (Mahtani, 2001, p. 101). The Multiculturalism Act declares Canadian media must reflect "the multicultural and multiracial nature of Canadian society and the special place of Aboriginal peoples within that society" (Multiculturalism Act, 1991), but there is no regulatory body to ensure these policies are enforced. The Canadian Broadcast Standards Council (CBSC), an organization created by private broadcasters, handles 
public complaints but none of the CBSC's seven industry codes of standards for TV and radio deal specifically with race (Canadian Broadcasting Standards Council, 2017). Instead, the CBSC focus on "issues relating to ethics, violence on television, equitable portrayals, journalistic ethics, cross media ownership, and pay television" (Canadian Broadcasting Standards Council, 2017, para. 1). Equitable portrayal focuses on achieving "fair" and "accurate" depictions, but it doesn't deal with underrepresentation. As a result, Canadian media often ignore this policy or underrepresent ethnic minorities (Mahtani, 2001, p. 104). Canadian TV shows with diverse casts such as Degrassi: The Next Generation (2001-2015) and Little Mosque on the Prairie (2007-2012) still "reproduced a framework of whiteness as the benchmark for Canadian identity" (Cho, 2012, pp. 6-7). This creates an us-versus-them divide between "real Canadians" and racialized minorities. Racialized groups are represented as "half humans", "others" or "foreigners" which may instill a sense of inferiority and shame regarding one's heritage (Mahtani, 2001, p. 104).

During the focus groups, participants felt that "Canadian" identity was reserved for white Canadians. Participants were asked beforehand to describe their racial and ethnic background. Asian and black participants struggled to locate themselves as Canadians or chose hyphenated identities such as "Asian Canadian" or "GhanaianCanadian." By comparison, white participants easily identified as Canadian or simply as "Caucasian" or "White." They didn't elaborate on their ethnic or racial heritage until witnessing others do so. Tuan argues this is common because white individuals are in a position of "social, political and economic privilege [and can choose] to ignore their racialization" (1998, p. 22). Ethnicity becomes flexible, voluntary, and is no longer 
central to their perception of identity (Waters, 1990). John ("white"), explained how his race goes unnoticed:

I'm from Russia but I've always considered myself white. I'm not ethnically identifiable and people here don't think I'm from anywhere. People think I'm Canadian. So when they ask where I'm from they're expecting, like, which part of the city.

McIntosh explains that in western societies white individuals carry an "invisible package of unearned assets" (1988, p. 30). They have the freedom to live, speak, move, and work freely. They are cultural insiders, never asked to speak on behalf of their race, and don't fear their whiteness will "work against them" in accessing public services, legal rights, or medical care (McIntosh, 1988, p. 33). John says people don't perceive him to be from "anywhere", which is a sign of freedom. White individuals like John can "belong" anywhere in western nations. But John and Tom ("Caucasian") felt that despite certain privileges, white individuals also face discrimination:

Tom: The moment [Canadians] learn I'm from the states, they hate me. [Canadians] are like, "You guys are so ridiculous." You keep saying how I cause all the world's problems and I'm like, "You know, America hasn't screwed up that much."

John: It's kind of like what you guys were mentioning... Do you fess up? Do I just say, "I've been in Ottawa as long as I can remember" and move on to the next question? Or "No, actually [I'm] Russian." Then immediately all the things in the world we could possible talk about zeros into what [Russians are] supposed to be familiar with.

But as the two illustrated, they have the option of choosing to disclose their backgrounds.

For racialized minorities there is no choice because their skin colour acts as an "inescapable marker of difference" (Tuan, 1998, p. 7). Take, for example, the way Sarah ("Canadian born Chinese") and Kelly ("Ghanaian-Canadian") describe how they are treated when travelling: 
Sarah: Every time [my family and I] leave Canada, or even within Canada, the first thing we get asked by [the locals] is, "Where are you from?" They'll try to speak either Korean, Japanese, or Chinese to us. They'll just yell it out across the street.

Kelly: If a white person asked me where I was from I would just say Toronto but when African [people] ask me where I'm from, like, a Nigerian guy walks up and is like, "Where are you from?" I was like, "Ahhhh." I really didn't know where I was from. Am I from Toronto? Am I from Ghana? I didn't know what to say.

Their skin colour marks them as outsiders, subject to verbal harassment, and without of a sense of belonging as they are forced to prove their loyalty to strangers. Racialized minorities tend to be "[disillusioned] with the shortcomings of integration" and possess a "deep pessimism concerning the likelihood of ever being judged solely by their character rather than by superficial physical differences" (Tuan, 1998, p. 7). But black participants said they didn't care. They recognized that the media and society may construct black people as inferior, but they were proud to be black.

\subsection{Black Canadian Identity}

As minorities, blacks and Asians may relate on some level but they have "undergone different racialization processes" (Tuan, 1998, p. 8). Black individuals have been in Canada since the seventeenth century and "were among the first non-indigenous residents" (Adbi, 2005, p. 50). During the American revolution (1765-1783), blacks living in British America were promised freedom from slavery if they fought for the British. Upwards to 30,000 blacks joined the British Army. After the British were defeated, 3,500 black loyalists were sent to Nova Scotia (The Arrival of the Loyalists in Canada, 2017). Between 1850 and 1860, an estimated 20,000 blacks escaped slavery in America and entered Canada via a number of secret routes known as the Underground Railroad (Adbi, 2005). Canada was viewed as the promised land because the 1793 Act to 
Limit Slavery declared black people free once they reached Upper Canada. They came to Canada willingly and as "free" people, but those who successfully crossed the border were met with discrimination, racism, and social and political exclusion (Adbi, 2005).

Ethnic identity research indicates that black families concerned about potential racism and stereotyping are more likely to build high self esteem and instill racial pride in their children (Hughes, Rodriguez, Smith, Johnson, Stevenson \& Spicer, 2006, p. 747). Exposure to cultural traditions, food, music, beliefs, holidays, and values are associated with a positive self identity (Rodriguez, McKay \& Bannon, 2008). But over time other influences, like peers and the media, will enter a child's life. The influence of one's parents begins to decrease and individuals start searching for independence and autonomy separate from their family (Huntemann \& Morgan, 2001, p. 312). Black participants displayed signs of ethnic and racial pride but they also struggled with how to reconcile their Canadian nationality:

Ruth: My parents definitely entrenched in me the fact that I am a Nigerian. I will not forget that. So when people ask me where I'm from I will say Nigeria, especially in Canada. I would go back to Nigeria and [my cousins] would be, like, "Oh, so where are you from?" And I would be kind of taken aback, like, "What do you mean where am I from?" They don't accept me as a Nigerian. When people ask me I still say Nigerian, automatically. It's the first thing that comes to my mind but sometimes when I'm in the company of ... younger Nigerians, I feel a little bit like I'm on the fringes, like I'm not really Nigerian.

Ada: I'm Congolese. My parents are from the Congo. That's just always how I've seen it. I don't feel like I'm from Ottawa. I'm Canadian. I'm born and raised here but at the same time I feel like if I say I'm Canadian it's like renouncing the other part of myself. Now we're living in this new world, right? Where it's, like, nationality and I guess blood, or ethnicity, or whatever, they're always conflicting. The ways we identify are morphing...I'm first generation [but] there's still some way of tracing me back to somewhere else...just as long as someone can look at me and say, "Where are you from?" 
Ruth and Ada talked about how their identities can shift and conflict, but they both underscore their African heritage. Ada suggests that she doesn't feel as though she really belongs in Canada: she's welcomed and she's grown up in Canada, but because of her physical features she's perceived as an outsider. She explained as a racialized minority her life "is always about [race]", whether she wants it to be or not. She chose to identify as Congolese because she felt society had a "imagined purity" for racialized minorities and that if one "deviate[s] from that then they're not [considered Asian enough or black enough] for some reason." Ada also felt Canadians can easily reject minorities when they no longer benefit the nation:

[Hypothetically] when you do something good [the Canadian media] will be like, "award-winning Canadian author." When I get arrested for, like, drunk driving they will use "the daughter of Congolese immigrants" even though I'm born here. They won't even try to tie me in any way to Canadian identity. They want you to be a Canadian when you're an advantage - economic, political, or social. When something bad happens...they unclaim you.

Puplampu and Tettey's (2005) study found that media commonly use ethnicity as a way to dissociate from minorities. Sprinter Ben Johnson went from being a "Canadian" to a “Jamaican-Canadian" after testing positive for banned substances during the 1988 Olympic games. Sometimes racialized minorities aren't even acknowledged as citizens. During the 1998 Winter Olympics Asian American figure skater, Michelle Kwan, was denied her American identity. MSNBC ran the headline "American Beats out Kwan" after Tara Lipinski's gold medal win in Women's figure skating (Wu, 2002). Both women are American but only Lipinski is acknowledged as such. The practice of using ethnic identifiers when referring to non-white individuals reinforces white people as legitimate members of society. Minorities are transformed into "undeserving intruders sponging off 
what real Canadians have achieved or held responsible for societies woes and told to 'go home"' (Puplampu and Tettey, 2005, p. 41). White Americans and Canadians are rarely subject to ethnic identifiers in media. But black participants rejected negative messages. They didn't want to assimilate or blend in, instead being like the dominant group was something to be avoided:

Kelly: My friends would call me whitewashed....I was raised in a predominantly black neighborhood. They talk in slang and stuff. One of my friends, I would text her and she would be like, "Why are you talking in this big English?" There's a group of black girls who make fun [of me]. They're always like, "You're so white." They mock me when I talk.

Kelly ("Ghanaian- Canadian") explained, although proud to be from Ghana, her identity is often questioned because she deviates from well known stereotypes. She felt mocked for not being "black enough" and explained, "[People think] I ditched my race, in a sense, [and] it pissed me off." Kelly felt "there are so many variations of black" but they aren't acknowledged in society, which made her "feel like shit." John ("white") admitted that he questioned Kelly's identity because her voice and affect reminded him of a teenaged, white girl:

I don't have very many black friends in my social circle all I see is what's on TV or YouTube...When Kelly started talking there was this dissociation in my head...I consider myself open minded and inclusive [but] I still had to like... "wait, no." That's totally possible [that she was born and raised in Ghana because]...you pick up [speech patterns] right away.

Kelly said, "When I talk to white people I'm thinking, 'Are they thinking I'm poor? Are they thinking I'm stupid?"' Kelly's comments show how she struggles to find her identity because of preconceived notions of what it means to be black. Cindy, a "Nigerian immigrant studying in Canada," also expressed feelings of confusion: 
I didn't grow up in Canada. I grew up in a place where you weren't racialized. Does that make sense? Because everybody was the exact same colour. So, all of us were black. I didn't even know what it meant to be black because everybody was black. But when I came here I realized that there were a lot of interesting ways that, like, people were racialized... [For racialized minorities in media there is] one category you have to fit in or you don't belong. It's annoying. Here, I am Nigerian.. but when I go back home it's like I'm Canadian...it's hard because I don't really know where I belong in this sense.

Cindy also struggles with her identity because of media representations, but also because she's currently living in Canada. Cindy noted frustration in the way that she is perceived by Canadians and Nigerians. Her comments suggest that she feels somewhat unaccepted by both cultures.

Black participants displayed a greater sense of belonging with their racial and ethnic heritage. They acknowledged influences from both parents and the media in shaping their identity. Their parents played a positive role by instilling racial pride, while the media played a negative role by stereotyping and disassociating black Canadians from Canadian identity. Blending in to Canadian culture was not important, but sometimes their nationality created tension with their black identity. Participants displayed a strong sense of pride in being black, whereas Caitlin, Sam, and Sarah chose to downplay their racial identity.

\subsection{Asian Canadian Identity}

Asian Americans are almost five times more likely to be mistaken as foreign or non-English speakers than white Americans (Cheryan \& Monin, 2005, p. 722). Because of their history and perceived physical differences, Asian Americans and Canadians are commonly viewed as outsiders by the media and society. East Asian participants identified as Canadian but acknowledged the media's reluctance to portray them as such 
or even at all. They displayed behaviours consistent with Cheryan and Monin's (2005) phenomenon of identity denial and Kim's (2012) Asian American racial identity development theory (AARID). They also blamed themselves for their portrayal in media and felt it was their responsibility to initiate social change.

Ethnic identity research suggests that when individuals realize they are in the minority they may experience internal conflict (Barretto, Spears, Ellemers \& Sahahinper, 2003; Cheryan \& Monin, 2005; Ellemers, Spears \& Doosje, 2002; Kim, 2012;

Phinney,1989; Schmitt \& Branscombe, 2001; Smith, 1991). Cheryan and Monin's (2005) study on identity denial found that when an individual does not "match the prototype of an in-group" their identity is "called into question or unrecognized by fellow group members" (p. 717). This disrupts one's fundamental need to belong and is associated with negative economic, health, and political consequences (Wang, Minervino \& Cheryan, 2012). Individuals may try to reassert their identity by explicitly identifying more strongly with the in-group. For example, they may use cultural knowledge or practices to "prove" in-group membership (Barretto et al., 2003), alter their behaviour and preferences to match the in-group, or attempt to distance themselves from their own ethnic or racial heritage (Ellemers, Spears \& Doosje, 2002; Schmitt \& Branscombe, 2001). These behaviours overlap with AARID, which outlines five stages that Asian Americans may experience as they come to understand their racial identity. Although the theory addresses Asian Americans, there are similarities between AARID and Asian Canadians who also spend their formative years in predominantly white societies. Evidence supporting this can be seen in the focus group discussions. 
The first stage of AARID is ethnic awareness and is described as a period where individuals begin to understand their ethnic background. Typically, stage one is present in young children who have yet to enter the school system. Their understanding and knowledge is generally shaped by family members. Stage two, white identification, is characterized as experiencing feelings of inferiority and a desire to assimilate. Individuals begin to realize they are different than their peers and may be teased. To avoid further public embarrassment they attempt to integrate. White societal values and standards are internalized. Sarah's ("Canadian Born Chinese") recollection of her childhood could be classified as typical of AARID's second stage:

For a long time when I was little, I really wanted to distance myself from Chinese culture because I was born in Ottawa. I was raised here. I'm surrounded by the Canadian culture.... I really wanted to fit in...it felt easier to do so if I called myself Canadian and distanced myself from being Chinese as opposed to highlighting that one difference.

Sarah felt she needed to conform to "Canadian culture" in order to gain social acceptance and cited her environment and family dynamic as major reasons for her "internalized racism." Sarah's lack of exposure to Chinese culture is typical of neutral feelings about ethnic membership, whereas greater exposure can lead to a greater sense of pride, security, and knowledge of one's cultural heritage (Kim, 2012). Sarah explained because she didn't see herself or people like her reflected in media she felt "left out", "lonely", and abnormal. Sam, another participant of East Asian descent, used her upbringing to further align herself with the dominant culture:

I am a third generation [Canadian] meaning my grandparents and greatgrandparents immigrated here. My parents are Canadian born. My experiences are extremely different. I don't eat Chinese food all the time at home. I usually eat western food. 
Asians may try to eliminate or repress their "Asianness" by actively identifying with white individuals (Cheryan \& Monin, 2005; Kim, 2012). Sam uses food as a way to confront perceived assumptions about Asians and to draw similarities between herself and white individuals. Sarah later displayed a sense of confidence in her Asian heritage, which would indicate further stages of AARID.

Stage three of AARID is an awakening to social political consciousness. Asians may become more knowledgeable and aware of their environment leading to a shift in the way they perceive themselves. They realize they are not personally responsible for racist behaviours or encounters, which enables them to let go of feelings of inferiority or guilt. They no longer feel the need to blend in or to diminish their ethnicity. Participants appeared to be socially and politically informed but did not relinquish feelings of inferiority or guilt. For example, Caitlin ("Canadian-born Chinese") felt Asians needed to be more proactive in order for media representations to improve:

I think us Asians kind of need to, like, get over ourselves and just start creating better content so we don't have to constantly be, like, "Are we being represented enough?" That's something I want to see personally from the East Asian community when they are creating stuff...I feel that even for Asians, Chinese, Koreans, whatever, they should feel that pressure to produce better content, not necessarily copying what's done by white America...I just think there's been so much bad...I have to pad my opinion based on that fact that they are minorities in the shot verses just critiquing character and storyline.

Similarly, Sarah insinuated the reason Asians have been long ignored in media is because of cultural differences:

I'm Chinese and we don't like to stir the pot. We don't like to talk about issues that are affecting us...I think that it's important that we have a voice as well. The Asian communities tend to be...we tend to stick our heads down and we don't really get involved in this type of stuff...Black people do get more representation and they are the face of racism but it's because they've worked for it...We have to fight for this type of stuff, you know? We can't expect this just to happen on its 
own...expecting black people to pull all of our own weight, we have to pull our own weight as well.

Sarah advocated strongly for increased visibility but her comments characterize Asians as passive and therefore somewhat responsible for the racism they've encountered. Sarah felt other racialized groups have successfully changed their perception in mainstream media because they've "worked for it." She blames Asians for not doing enough. But Asians have been advocating for equality since the late 1960s. Caitlin and Sarah acknowledged systemic barriers but still blamed Asians for their absence in mainstream media.

Stage four is a redirection to Asian American consciousness. Individuals begin to see themselves as part of society, as Americans or Canadians of Asian origin. Stage five, incorporation, is where one disowns the "dominant group's views of their race and [develops] a positive self definition and a positive attitude toward their own group (Kim, 2012, p. 148). They have resolved internal conflicts and are confident in their racial identity. At times, East Asian participants displayed a positive attitude towards their own group. They were insightful and thoughtful and saw themselves as valuable members of society. But they also contradicted themselves or behaved in ways that were counter to their statements. For example, some felt Asians needed to be more proactive in order to improve representations, but then participants chose to repress their identity and align with the in-group in society. They also criticized media representations for not being reflective of their experiences, but then cringed when they saw Asians being bullied because of their own "bad memories." Kim notes that racial identity development is a lifelong process and that although an individual may have "completed" one stage an event or behavioural response may bring them back to a previous stage (2012, p. 149). 
Most East Asian participants acknowledged their perception as outsiders in media. Their behaviours suggested that to some degree they have internalized these messages because they displayed signs consistent with identity denial and AARID. Participants displayed signs of stage two, white identification, by trying to identify more closely with the in-group in society. They downplayed their ethnic and racial identity and used their preferences to show similarities between themselves and white Canadians. Stage three is an awakening to political consciousness and an understanding that racist encounters are not their fault. At times participants were confident and self-assured in their Asian identity, but they also maintained feelings of guilt. They felt Asians needed to be more proactive in advocating and producing quality content in order to improve their perception in media. The contradiction underscores the fluid nature of identity, which is constantly renegotiated and modified as participants move through experiences.

In Canada, the relationship between identity formation and media is especially complex. Multiculturalism offers the illusion of equality and tolerance, but Canadian policies and legislation have largely failed to achieve equality because racism is deeply embedded into Canadian norms and practices. White participants discussed how easily they could live, work, and play in western spaces, whereas racialized minorities felt they weren't afforded the same privileges because their physical differences marked them as "outsiders." Canadian media promote the image of white Canadians as the standard and isolate ethnic minorities. Despite this, black participants were proud of their racial and ethnic heritage. They acknowledged feeling confused about how their Canadian nationality fit within their overall sense of identity but ultimately identified more strongly with their ethnic and racial roots. They didn't particularly want to assimilate into 
Canadian society, whereas east Asian participants did. East Asian participants attempted to reassert their identity by identifying more strongly with Canadian culture. These behaviours suggest internal conflict and are consistent with identity denial and ARRID. Most participants struggled with some aspect of their racial, ethnic, or national identity in relation to Canadian media and policies. This highlights the increasingly important role the media play in the construction of reality. The final chapter addresses the significance of the results by discussing how they relate to existing scholarship on race, media, and identity and by identifying areas for further research. 


\section{Chapter: Conclusion}

After Margaret Cho's All American Girl was cancelled, she joked that the only Asian role model she had growing up was an anthropomorphic cat named Hello Kitty. ${ }^{10}$ TV has a profound impact on the way we understand ourselves and those around us. For decades, Asian Americans and Canadians were excluded from mainstream media. Asians weren't given the time, space, or opportunity to tell their stories. Role models were rare, and shows led by Asian Americans or Canadians were non-existent. Asian characters were relegated to the margins, added for comedic effect or to serve as set decoration. But for the twenty million individuals of Asian descent living in North America, this reinforced the idea that Asians were inferior. Asian Americans and Canadians were perceived as outsiders by mainstream media, which disrupts one's fundamental sense of belonging. And as some participants demonstrated, if these messages are internalized individuals may experience internal conflict or have a limited understanding of what's possible for Asian Americans and Canadians in terms of social, economic, and political opportunities.

Negative representations in media are associated with negative psychological impacts but under certain conditions positive images can be used to improve attitudes and reduce prejudice. In recent years, TV has made a conscious effort to diversify. Asians are becoming more visible onscreen. This thesis explored how Canadian university students are making sense of diverse images of Asian Americans and Canadians on network and web television series and the impact of representations on their sense of identity. Focus

\footnotetext{
${ }^{10}$ Hello Kitty was created in 1974 by Sanrio. In 2014, Sanrio revealed Hello Kitty is actually a felinemorphic human girl named Kitty White.
} 
groups were used to investigate because the method allows individuals to express how and why they may feel a particular way. The data resulted in three major findings: (1) participants relied on stereotypes to make sense of Asian American and Canadian representations; (2) participants downplayed the role of media in society; and (3) participants struggled to understand their ethnic, racial, and national identity.

I anticipated that participants would react positively to diverse images of Asian Americans and Canadians in media, but the findings did not support this. Widespread stereotypes made a bigger impact on most participant interpretations than the content of the clips themselves. East Asian participants were frustrated because they felt society perceived of them in stereotypical ways. At times some East Asian participants displayed a sense of awareness and confidence in their racial identity, but they also wanted to prove: (1) their membership with the in-group, and (2) that stereotypes didn't define them. They rejected most clips by saying they were not reflective of their experiences and attempted to distinguish themselves as members of mainstream Canadian society. One participant used their family history and adoption of Canadian customs as proof of their status. Two alternative explanations as to why participants deferred to stereotypes could be because of (1) various social identities and (2) the focus group format. There is a wide range of diversity among racialized communities. For example, individuals who identify as Chinese Canadians have other social identities, like gender, class, age, and sexual orientation that impact the way they make sense of representations. Second, the focus group dynamic could have influenced participants to behave in specific ways. They may have been persuaded by other research participants. Some may have embellished experiences in order to fit in or to purposely challenge others. 
This project contributes to existing scholarship by calling attention to the relationship between media representations and Asian Canadian identity formation. Asian American and Canadians are often absent from ethnic and racial studies in mainstream media. This research provide insights into how young adults are making sense of recent moves in Hollywood to diversify. The results highlighted the media's role in identity denial and illustrated the lack of understanding young adults may have about the material conditions that shape images. The results make a case for continued efforts from media activists, scholars, and policy makers to encourage diverse representations and to improve media literacy education.

This thesis also builds on existing studies of race and media by using similar techniques to explore underdeveloped areas. For example, Mahtani (2001) acknowledges the relationship between identity formation and media is especially complicated in Canada because multiculturalism often renders institutionalized racism invisible. And Sun et al. found that the impact of diverse Asian images may be "limited" (2015, p. 296). Tukachinsky notes that prejudice reduction via positive images is difficult due to "complex psychological mechanisms" that make normalized perceptions "stable and resistant to change" (2015, p. 189). If individuals don't feel change is possible they may rationalize the lack of diversity in media as a way to resolve "cognitive dissonance" (Sun at al., 2015, p. 309). In this study East Asian participants blamed themselves for the lack of Asian representations, despite the increase in diversity. Other participants downplayed the significance of representations altogether. These findings differ by highlighting how diverse representations of ethnic minorities are interpreted. The findings indicate there 
may be differences in the way Canadians interpret representations of racialized groups and that stereotypes may be more significant for some in terms of making meaning.

\subsection{Limitations}

Due to the size of this project and time constraints, this research had many limitations. I opted to conduct two focus groups but three or more could have provided a much richer data set. Smaller groups (six or less) or longer sessions may also be beneficial. I felt the non-Asian session (eleven participants) was too large. Three participants dominated the conversation making it difficult for others to contribute, which may have skewed the results. Additionally, my sample size was confined to Carleton University students who felt comfortable talking about race in small groups, but for a fuller picture I could have extended my recruitment to other post secondary institutions, as well as young adults not attending post secondary. Moreover, this study took place in Ottawa, Canada, which is the nation's fourth largest city with a population of 1.2 million (Statistics Canada, 2011). But only nineteen per cent identify as part of a "visible minority" (Statistics Canada, 2011). A larger and more diverse city, like Montreal, Toronto, or Vancouver, could provide interesting data because of the increase in exposure to cultural diversity. Alternatively a smaller community could also provide significant insights due to their limited exposure to racial and ethnic diversity. Additionally, my presence as an individual of Asian descent may have also limited or influenced the ways participants talked about Asian representations. An alternative may be to use a moderator, however, I felt participants were still very forthcoming and unfiltered.

These aspects are somewhat unpredictable. No one can calculate how a focus group will unfold. There's a level of uncertainty when recruiting and interacting with 
participants, therefore, it's important to acknowledge that ideas or patters that emerge from this focus group may be unique to a specific subset of individuals. The ability to identify larger trends and patterns is important but so is examining small groups of people, especially in the case of Asian Americans and Canadians who have been deemed "negligible" in media by previous studies. Studies that look to understand a specific group can help widen the overall size and scope of ethnic minority research.

\subsection{Future Research}

Because existing research on the relationship between Asian representations in media and identity formation is limited, there are many areas that can be further explored. To expand on this study, future researchers could organize each focus group by ethnicity and race, as opposed to using a single non-Asian session for comparison. This may highlight trends that are specific to certain cultural groups. Alternatively, future studies could look at the differences in terms of Canadian-born ethnic minorities and those who immigrated to Canada. In terms of expanding on the identity aspect of this study, future research could incorporate in-depth interviews, in addition to focus groups, as a way to further understand the subject positions of participants and how various factors may influence their perception and way meaning in constructed.

Additionally, two related areas that could benefit from future research are streaming services and prejudice reduction. Messages and representations seen on television are not consistent with other texts such as streaming services and user generated content (YouTube) (Mastro, 2015). These areas can be studied to provide a fuller picture on the effects of representation as TV shifts towards a more digital future (Molina-Guzman, 2016, p. 451). One of the major differences with streaming services is 
that they don't have to satisfy advertisers. They have their own distribution channels and therefore the freedom to tell different kinds of stories. Netflix and Hulu strategically target ethnic and minority audiences through original and pre-existing programming. For example, Netflix's Narcos (2015 - present), Orange is the New Black (2013 - present), Dear White People (2017 - present), and Hulu's East Los High (2013 - 2017) and The Mindy Project (2012 - present) highlight the nuanced and rich experiences of groups not often seen on network television. These shows are also pushing boundaries off screen. For instance, East Los High was created by an all Latino production, directing, and writing team (Molina-Guzman, 2016). These changes put pressure on ad-dependent networks to diversify, which can potentially shift power structures (Molina-Guzman, 2016, p. 451). Thousands of Canadians have already ended their subscription to cable in favour of digital streaming, so it would be interesting to measure the influence of these shows on major studios and networks and to investigate whether digital streaming can tackle bigger issues like cultural hegemony.

Prejudice reduction and the use of positive images to offset normalized stereotypes is another area that could be explored. Specifically, more research to determine under what conditions are these practices effective. Various theories suggest media images have the potential to change attitudes, such as Greenberg's drench hypothesis (1998) and Ramasubramanian's (2015) and Tukachinsky's (2015) work on counter exemplars in media, but each has various conditions that must be met in order for prejudice to be reduced or for attitudes to change. Further research is needed to determine how exactly prejudice reduction through media can impact attitudes, beliefs, and perceptions. Acknowledging the absence or negative portrayals of ethnic minorities in 
media makes institutionalized racism, cultural hegemony, and the negative psychological effects of media more visible. Increased awareness puts pressure on the cultural industries to improve representations, on the education system to develop a more comprehensive media literacy curriculum, and on audiences to be more critical of the media they consume. Hollywood is currently in the midst of some major changes. The lack of diversity in the cultural industries needs to continue to be an important issue for activists, academics, audiences, and policy makers in order for lasting change to industry standards to occur. 


\section{References}

Abdi, A. A. (2005). Reflections on the long struggle for inclusion: The experiences of people of African origin. In W. J. Tettey \& K. P. Puplampu (Eds.), The African diaspora in Canada: Negotiating identity and belonging (pp. 49-60). Calgary, AB: University of Calgary Press.

Adachi, J. (Producer), \& Adachi, J. (Director). (2006). The slanted screen: Asian men in film and television. [Motion picture]. United States: Asian American Media Mafia Productions.

Alexandrin, J. R. (2009). Television images: Exploring how they affect people's view of self and others. Multicultural Perspectives, 11(3), 150-154.

Appelo, T. (2015, June 23). Emmy breakout Constance Wu is not 'Fresh Off the Boat's' tiger mom: Watch her \#selfieinterview. The Wrap. Retrieved from http://www.thewrap.com/emmy-breakout-constance-wu-is-not-fresh-off-theboats-tiger-mom-watch-her-selfieinterview-video/

Ash, M. C. (2004). But where are you really from? Reflections on immigration, multiculturalism, and Canadian identity. In C. Nelson \& C.A. Nelson (Eds.), Racism, Eh?: A critical interdisciplinary anthology of race and racism in Canada (pp. 398-409). Concord, ON: Captus Press Inc.

Ashmore, R.D., \& Del Boca, F. K. (2015). Conceptual approaches to stereotypes and stereotyping. In D. L. Hamilton (Ed.), Cognitive processes in stereotyping and intergroup behavior (pp. 1-36). NY: Psychology Press.

Aufderheide, P. (Ed.). (1993). Media literacy: A report of the national leadership conference on media literacy. Aspen, CO: Aspen Institute.

Baker, D. G. (1983). Race, ethnicity, and power: A comparative study. Routledge.

Bandura, A. (2002). Social cognitive theory in cultural context. Applied Psychology, 51(2), 269-290.

Bannerji, H. (2000). The dark side of the nation: Essays on multiculturalism, nationalism and gender. Toronto, ON: Canadian Scholars' Press.

Barreto, M., Spears, R., Ellemers, N., \& Shahinper, K. (2003). Who wants to know? The effect of audience on identity expression among minority group members. British Journal of Social Psychology, 42(2), 299-318.

Bates, T. R. (1975). Gramsci and the theory of hegemony. Journal of the History of Ideas, 35(2), 351-366. 
Bhabha, H. (1990). Interview with Homi Bhabha. In J. Rutherford (Ed.), Identity:

Community, culture, difference (pp. 207-221). London: Lawrence and Wishart.

Bodenhausen, G. V., Schwarz, N., Bless, H., \& Wänke, M. (1995). Effects of atypical exemplars on racial beliefs: Enlightened racism or generalized appraisals. Journal of Experimental Social Psychology, 31(1), 48-63.

Boboltz, S. \& Yam, K. (2017, February 24). Why on-screen representation actually matters. HuffPost. Retrieved from http://www.huffingtonpost.ca/entry/why-onscreen-representation-matters_us_58aeae96e4b01406012fe49d

Boggs, C. (1976). Gramsci's Marxism. Pluto Press.

Boone Isaacs, C.B. (2016, January 18). Statement from academy president Cheryl Boone Isaacs. Academy of Motion Picture Arts and Sciences. Retrieved from http://www.oscars.org/news/statement-academy-president-cheryl-boone-isaacs

Braun, V., \& Clarke, V. (2006). Using thematic analysis in psychology. Qualitative Research in Psychology, 3(2), 77-101.

Buchignani, N. (1979). South Asian Canadians and the ethnic mosaic: An overview. Canadian Ethnic Studies, 11(1), 48-68.

Bullock, K. H., \& Jafri, G. J. (2000). Media (mis)representations: Muslim women in the Canadian nation. Canadian Woman Studies, 20(2), 35-40.

Canadian Broadcast Standards Council (2017). About Us. Retrieved from http://www.cbsc.ca/about-us/

Canadian Charter of Rights and Freedoms, s15, Part I of the Constitution Act, 1982,being Schedule B to the Canada Act 1982 (UK), 1982, c11.

Chan, C. S. (1988). Asian-American women: Psychological responses to sexual exploitation and cultural stereotypes. Women \& Therapy, 6(4), 33-38.

Chan, J. (2001). Chinese American masculinities: From Fu Manchu to Bruce Lee. New York, NY: Routledge.

Cheryan, S., \& Bodenhausen, G. V. (2000). When positive stereotypes threaten intellectual performance: The psychological hazards of "model minority" status. Psychological Science, 11(5), 399-402.

Cheryan, S., \& Monin, B. (2005). Where are you really from?: Asian Americans and identity denial. Journal of Personality and Social Psychology, 89(5), 717- 730. 
Cho, H. (2012). Representations of diversity in Canadian television entertainment programming: Case studies. Media Action Media. Retrieved from http://www.media-action-media.com/wpcontent/uploads/2012/05/MAM _Diversity-Research-Report_FINAL.pdf

Chow, K. (2017, April 19). 'Model minority' myth again used as a racial wedge between Asians and blacks. NPR. Retrieved from http://www.npr.org/sections /codeswitch/2017/04/19/524571669/model-minority-myth-again-used-as-a-racialwedge-between-asians-and-blacks

Chow, K. (2015, February 12). 'Community' actor Ken Jeong might be getting his own show. NPR. Retrieved from http://www.npr.org/sections/codeswitch/2015/02/ 12/385740978/ community-actor-ken-jeong-might-be-getting-his-own-show

Chu, A. (2015, May 15). Eddie Huang self-destructs: Why the "Fresh Off the Boat" author's descent into misogyny is so depressing. Salon. Retrieved from http://www.salon.com/2015/05/15/eddie_huang_self_destructs_why_the _fresh_off_the_boat_authors_descent_into_misogyny_is_so_depressing_partner/

Collins, P. H. (2002). Black feminist thought: Knowledge, consciousness, and the politics of empowerment. New York, NY: Routledge.

Coltrane, S., \& Messineo, M. (2000). The perpetuation of subtle prejudice: Race and gender imagery in 1990s television advertising. Sex roles, 42(5), 363-389.

Comstock, G. (1993). The medium and the society: The role of television in American life. In G.L. Berry \& J.K. Asamen (Eds.), Children and television: Images in a changing sociocultural world. (pp.117-131). Newberry Park, CA: Sage Publications.

Costigan, C. L., Su, T. F., \& Hua, J. M. (2009). Ethnic identity among Chinese Canadian youth: A review of the Canadian literature. Canadian Psychology, 50, 261-272.

Creswell, J. W., \& Poth, C. N. (2017). Qualitative inquiry and research design: Choosing among five approaches. Thousand Oaks, CA: Sage publications.

Dates, J. L., \& Stroman, C. A. (2001). Portrayals of families of color on television. In J. Bryant \& A. Bryant (Eds.), Television and the American family (pp. 207-228). Mahwah, NJ: Lawrence Erlbaum Associates.

Ellemers, N., Spears, R., \& Doosje, B. (2002). Self and social identity. Annual Review of Psychology, 53(1), 161-186. 
Erikson, E. H. (1959). Identity and the life cycle. New York: International Universities Press.

Erikson, E. H. (1968). Identity: Youth and crisis. New York: W. W. Norton.

Ge, L. (2015, September 29). How ABC is trailblazing path for Asians on TV with 'Fresh off the Boat,' 'Dr. Ken,' 'Quantico'. The Wrap. Retrieved from $\mathrm{http}$ ://www.thewrap.com/how-abc-is-trailblazing-path-for-asians-on-tv-withfresh-off-the-boat-dr-ken-quantico/

Gerbner, G., \& Gross, L. (1976). Living with television: The violence profile. Journal of Communication, 26(2), 172-194.

Gerbner, G., Gross, L., Morgan, M., Signorielli, N., \& Shanahan, J. (2002). Growing up with television: Cultivation processes. In J. Bryant \& D. Zillmann (Eds.), Media effects: Advances in theory and research (pp.43-67). Mahwah, NJ: Lawrence Erlbaum Associates, Inc.

Glaser, B. G. (1965). The constant comparative method of qualitative analysis. Social Problems, 12(4), 436-445.

Greenberg, B. S. (1988). Some uncommon television images and the drench hypothesis. In S. Oskamp (Ed.), Television as a social issue (pp. 88-102). Thousand Oaks, CA: Sage Publications.

Greenberg, B. S., \& Baptista-Fernandez, P. (1980). Hispanic-Americans: The new minority on television. In B.S. Greenberg (Ed.), Life on television: Content analysis of US TV drama (pp. 173 - 181). Norwood, NJ: Ablex.

Graves, S.B. (1996). Diversity on television. In T.M. MacBeth (Ed.), Tuning in to young viewers (pp.61-86). Thousand Oaks, CA: Sage Publications.

Hall, S. (1997). Representation: Cultural representations and signifying practices. Sage.

Hall, S. (1992). Race, culture, and communications: Looking backward and forward at cultural studies. Rethinking Marxism, 5(1), 10-18.

Halualani, R. T., \& Vande Berg, L. R. (1998). Asian or American: Meanings, in, through, and around All-American girl. In L.R. Vande Berg, L. Wenner \& B. Gronbeck (Eds.), Critical approaches to television (pp.214-235). Boston, MA: Houghton Mifflin.

Hamamoto, D. Y. (1994). Monitored peril: Asian Americans and the politics of TV representation. Minneapolis, MN: University Of Minnesota Press. 
Hammer, R. (2009). This won't be on the final: Reflections on teaching critical media literacy. In R. Hammer \& D. Kellner (Eds.), Media/cultural studies: Critical approaches (pp. 164-193). New York, NY: Peter Lang Publishing.

Harwood, J., \& Vincze, L. (2015). Ethnolinguistic identification, vitality, and gratifications for television use in a bilingual media environment. Journal of Social Issues, 71(1), 73-89.

Henry, F., \& Tator, C. (1999). State policies and practices as racialized discourse: Multiculturalism, the Charter and employment equity. In P.S. Li (Ed.), Race and ethnic relations in Canada (pp. 88-115). Toronto, ON: Oxford University Press.

Hess, A. (2016, May 25). Asian Americans are fighting for visibility. They will not be ignored. The New York Times. Retrieved from https://www.nytimes.com/2016 /05/29/movies/asian-american-actors-are-fighting-for-visibility-they-will-not-beignored.html

Hewstone, M., Johnston, L., \& Aird, P. (1992). Cognitive models of stereotype change: (2) Perceptions of homogeneous and heterogeneous groups. European Journal of Social Psychology, 22(3), 235-249.

Ho, K. (2015, April 12). Fresh Off the boat: what do we want out of an Asian American TV show?.Huff Post. Retrieved from http://www.huffingtonpost.com/khanhho/fresh-off-the-boat-what-do-asian-american_b_6649104.html

Hobbs, R., \& Jensen, A. (2009). The past, present, and future of media literacy education. Journal of Media Literacy Education, 1(1), 1-11.

Huang, A. (2006). The silent spikes: Chinese laborers and the construction of North American railways. China Intercontinental Press.

Huang, E. (2015, February 4). Bamboo-ceiling TV. Vulture. Retrieved from http://www.vulture.com/2015/01/eddie-huang-fresh-off-the-boat-abc.html

Hughes, D., \& DuMont, K. (1993). Using focus groups to facilitate culturally anchored research. American Journal of Community Psychology, 21(6), 775-806.

Hughes, D., Rodriguez, J., Smith, E. P., Johnson, D. J., Stevenson, H. C., \& Spicer, P. (2006). Parents' ethnic-racial socialization practices: A review of research and directions for future study. Developmental Psychology, 42(5), 747-770.

Hunt, D.M. (2002). Prime time in black and white: Making sense of the 2001 fall season. Los Angeles, CA: Ralph J. Bunche Center for African American Studies, UCLA. 
Hunt, N. (2016, October 1). Breaking new ground: Kim's Convenience to be Canada's 1st sitcom led by Asians. CBC News. Retrieved from http://www.cbc.ca/news/ entertainment/kims-convenience-diversity-1.3783998

Hunt, D.M., Ramon, A.C., Tran, M., Sargent, A., \& Diaz, V. ( 2017). 2017 Hollywood Diversity Report : Setting the record straight. Los Angeles, CA: Ralph J. Bunche Center for African American Studies at UCLA.

Hunt, D. M., Ramon, A. C., \& Price, Z. (2014). 2014 Hollywood diversity report: Making sense of the disconnect. Los Angeles, CA: Ralph J. Bunche Center for African American Studies, UCLA.

Huntemann, N., \& Morgan, M. (2001). Mass media and identity development. In D. Singer \& J. Singer (Eds.), Handbook of children and the media (pp. 309-323). Thousand Oaks, CA: Sage Publications.

Indigenous and Northern Affairs Canada (2017). Government of Canada. Retrieved from https://www.aadnc-aandc.gc.ca/eng/1100100010023/1100100010027

The Immigration and Nationality Act of 1965 (H.R. 2580; Pub.L. 89-236, 79 Stat. 911).

Itwaru, A., \& Ksonzek, N. (1994). Closed entrances: Canadian culture and imperialism. Toronto, ON: TSAR Publications.

Jung, A.E. (2015, November 11). 2015: The year Asian Americans finally got a shot on TV. Vulture. Retrieved from http:/www.vulture.com/2015/11/asian-americanson-tv-2015.html

Kang, I. (2016, December 15). 2016 was TV's most diverse year ever - and not coincidentally, one of its best. MTV. Retrieved from http:/www.mtv.com/news/ 2964614/2016-was-tvs-most-diverse-year-ever/

Kay, A. C., Day, M. V., Zanna, M. P., \& Nussbaum, A. D. (2013). The insidious (and ironic) effects of positive stereotypes. Journal of Experimental Social Psychology, 49(2), 287-291.

Kim, J. (2012). Asian American racial identity development theory. In C. Wijeyesinghe \& B. Jackson (Eds.), New perspectives on racial identity development (pp. 138160). New York, NY: New York University Press.

Kirmayer, L., Simpson, C., \& Cargo, M. (2003). Healing traditions: Culture, community and mental health promotion with Canadian Aboriginal peoples. Australasian Psychiatry, 11(1), 15-23. 
Kitzinger, J. (1995). Qualitative research. Introducing focus groups. BMJ: British Medical Journal, 311(7000), 299 - 302.

Krueger, R. A., \& Casey, M.A. (2014). Focus groups: A practical guide for applied research. Thousand Oaks, CA: SAGE Publications.

Lai, C. D. (2011). A brief chronology of Chinese Canadian history: From segregation to integration:1788-2010. Simon Fraser University David See-Chai Lam Centre for International Communication. Retrieved from http://www.sfu.ca/chinesecanadian-history/chart_en.html

Laurendeau, A., Dunton, D. (1967-1970). Report of the royal commission on bilingualism and biculturalism, 6 vols. Ottawa, ON: Queen's Printer.

Leavitt, P. A., Covarrubias, R., Perez, Y. A., \& Fryberg, S. A. (2015). "Frozen in time": The impact of Native American media representations on identity and self-understanding. Journal of Social Issues, 71(1), 39-53.

Lee, A. (2016, October 10). Kim's Convenience: A TV first that doesn't buckle under the pressure. MacLean's. Retrieved from http://www.macleans.ca/culture/ television/kims-convenience-a-tv-first-that-doesnt-buckle-under-the-pressure/

Lee, S. J. (2015). Unraveling the "model minority" stereotype: Listening to Asian American youth. New York, NY: Teachers College Press.

Lewis, J., \& Jhally, S. (1998). The struggle over media literacy. Journal of Communication, 48(1), 109-120.

Li, P. S. (1988). The Chinese in Canada. Toronto, ON: Oxford University Press.

Li, P.S. (2000). Cultural diversity in Canada: The social construction of racial differences. Department of Justice Canada. Retrieved from http://www.justice.gc.ca/eng/rp-pr/csj-sjc/jsp-sjp/rp02_8-dr02_8/rp02_8.pdf

Liamputtong, P. (2011). Focus group methodology: Principle and practice. Sage Publications.

Library and Archives Canada. (2009). Early Chinese Canadians, 1858-1947. Retrieved from http://www.bac lac.gc.ca/eng/discover/immigration/history-ethniccultural/early- chinese-canadians/Pages/introduction.aspx

Library and Archives Canada. (2009). Japanese. Immigration history: Ethnic and cultural groups. Retrieved from http://www.baclac.gc.ca/eng/discover/ immigration/history-ethnic-cultural/Pages/japanese.aspx\#f 
Lippmann, W. (1922). Public opinion. New York, NY: Harcourt, Brace and Co.

Lull, J. (1995). Media, communication, culture: A global approach. Cambridge, UK: Polity Press.

MacDonald, J. F. (1992). Black and white television: African Americans in television since 1948. (2nd ed.). Chicago: Nelson-Hall Publishers.

Mackey, E. (2002). The house of difference: Cultural politics and national identity in Canada. Toronto, ON: University of Toronto Press.

Mahtani, M. (2001). Representing minorities: Canadian media and minority identities. Canadian Ethnic Studies, 33(3), 99- 133.

Marchetti, G. (1994). Romance and the "yellow peril": Race, sex, and discursive strategies in Hollywood fiction. Berkley, CA: University of California Press.

Marcia, J. E. (1966). Development and validation of ego-identity status. Journal of Personality and Social Psychology. 3 (5), 551-558.

Mastro, D. (2015). Why the media's role in issues of race and ethnicity should be in the spotlight. Journal of Social Issues, 71(1), 1-16.

Mastro, D. E., \& Greenberg, B. S. (2000). The portrayal of racial minorities on prime time television. Journal of Broadcasting \& Electronic Media, 44(4), 690-703.

McIntosh, P. (1988). White privilege: Unpacking the invisible knapsack. In A.M. Filor (Ed.) Multiculturalism (pp.30-36). NY: New York State United Teachers.

Merskin, D. (2004). Reviving Lolita? A media literacy examination of sexual portrayals of girls in fashion advertising. American Behavioral Scientist, 48(1), 119-129.

Mok, T. A. (1998). Getting the message: Media images and stereotypes and their effect on Asian Americans. Cultural Diversity and Mental Health, 4(3), 185 - 202.

Molina-Guzmán, I. (2016). \# OscarsSoWhite: How Stuart Hall explains why nothing changes in Hollywood and everything is changing. Critical Studies in Media Communication, 33(5), 438-454.

Multiculturalism Act, R.S.C., 1985, c.24. (4th Supp.).

Ono, K. A., \& Pham, V. N. (2009). Asian Americans and the media. Cambridge, UK: Polity. 
Onwuegbuzie, A. J., Dickinson, W. B., Leech, N. L., \& Zoran, A. G. (2009). A qualitative framework for collecting and analyzing data in focus group research. International Journal of Qualitative Methods, 8(3), 1-21.

Ortlipp, M. (2008). Keeping and using reflective journals in the qualitative research process. The Qualitative Report, 13(4), 695-705.

Otterson, J. (2017, May 12). 'Speechless,' 'Fresh Off the Boat' renewed at ABC. Variety. Retrieved from http://variety.com/2017/tv/news/speechless-renewed$1202421120 /$

Phinney, J. S. (1989). Stages of ethnic identity development in minority group adolescents. The Journal of Early Adolescence, 9(1-2), 34-49.

Puplampu, K.P., \& Tettey, W. (2005). Ethnicity \& the identity of African Canadians: A theoretical and political analysis. In W. Tettey \& K.P. Puplampu (Eds.), The African diaspora in Canada: Negotiating identity \& belonging (pp. 26-48). Calgary, CA: University of Calgary Press.

Ramasubramanian, S. (2015). Using celebrity news stories to effectively reduce racial/ethnic prejudice. Journal of Social Issues, 71(1), 123-138.

Rao, S. (2016, October 11). How 'Fresh off the Boat' executive producer Melvin Mar helped change Hollywood behind the scenes. Color Lines. Retrieved from http://www.colorlines .com/articles/how-fresh-boat-executive-producer-melvinmar-helped-change-hollywood-behind-scenes

Richards, Z., \& Hewstone, M. (2001). Subtyping and subgrouping: Processes for the prevention and promotion of stereotype change. Personality and Social Psychology Review, 5(1), 52-73.

Rodriguez, J., McKay, M.M., \& Bannon, W.M. (2008). The role of racial socialization in relation to parenting practices and youth behavior: An exploratory analysis. Social Work in Mental Health, 6(4), 30-54.

Rottenberg, J. (2017, January 24). 'La La Land,' diversity and the return of Mel Gibson: the highlights of the 2017 Oscar nominations. Los Angeles Times. Retrieved from http://www.latimes.com/entertainment/movies/la-et-mn-oscar-nominations-mainnews-story-20170124-story.html

Ryan, M. (2016, February 23). Why television is embracing diversity and the realities of race. Variety. Retrieved from http://variety.com/2016/tv/features/television-racediversity-ratings-1201712266/

Said, E. W. (1978). Orientalism. New York, NY: Pantheon Books. 
Scharrer, E., \& Ramasubramanian, S. (2015). Intervening in the media's influence on stereotypes of race and ethnicity: The role of media literacy education. Journal of Social Issues, 71(1), 171-185.

Schmader, T., Block, K., \& Lickel, B. (2015). Social identity threat in response to stereotypic film portrayals: Effects on self-conscious emotion and implicit ingroup attitudes. Journal of Social Issues, 71(1), 54-72.

Schmitt, M. T., \& Branscombe, N. R. (2001). The good, the bad, and the manly: Threats to one's prototypicality and evaluations of fellow in-group members. Journal of Experimental Social Psychology, 37(6), 510-517.

Schneider, D. J. (2004). The psychology of stereotyping. New York, NY: Guilford Press.

Shim, D. (1998). From yellow peril through model minority to renewed yellow peril. Journal of Communication Inquiry, 22(4), 385-409.

Siebel-Newsom, J. S., \& Costanzo, J. (Producer) \& Newsom, J.S. (Director). (2011). Miss representation. [Motion picture]. United Stated: Girls' Club Entertainment.

Smith, A. D. (1991). National identity. Reno, NV: University of Nevada Press.

Smith, S. L., Choueiti, M., \& Pieper, K. (2016). Inclusion or invisibility? Comprehensive Annenberg report on diversity in entertainment. Institute for Diversity and Empowerment at Annenberg: USC Annenberg School for Communication and Journalism. Retrieved from http://annenberg.usc.edu/pages/ /media/MDSCI/ CARDReport\%20FINAL\%2022216.ashx

Spencer, S. (2014). Race and ethnicity: Culture, identity and representation. New York, NY: Routledge.

Statistics Canada. (2011). Immigration and ethnocultural diversity in Canada. Retrieved from http://www12.statcan.gc.ca/nhs-enm/2011/as-sa/99-010-x/99-010x2011001-eng.cfm

Stewart, D. (2011, November 15). Community is important, and not just because it's great. Jezebel. Retrieved from http://jezebel.com/5859651/nbc-will-be-making-ahuge-mistake-if-it-cancels-community

Sue, D. W., Bucceri, J., Lin, A. I., Nadal, K. L., \& Torino, G. C. (2007). Racial microaggressions and the Asian American experience. Cultural Diversity and Ethnic Minority Physiology, 13 (1), 72-81. 
Sun, C., Liberman, R., Butler, A., Lee, S. Y., \& Webb, R. (2015). Shifting Receptions: Asian American stereotypes and the exploration of comprehensive media literacy. The Communication Review, 18(4), 294-314.

Sundar, P. (2008). To "brown it up" or to "bring down the brown": Identity and strategy in second-generation, South Asian-Canadian youth. Journal of Ethnic \& Cultural Diversity in Social Work, 17(3), 251-278.

Tobin, J. J. (2000). "Good guys don't wear hats": Children's talk about the media. New York, NY: Teachers College Press.

Tobin, J.J. (1995). Post-structural research in early childhood education. In J.A. Hatch (Ed.), Qualitative research in early childhood settings (pp.223-224). Westport, CT: Praeger.

Tsai, D. (2014, June 5). Video: Eddie Huang on why Fresh Off the Boat uses racial slurs. TIME. Retrieved from http://time.com/2826633/eddie-huang-fresh-off-the-boatinterview/

Tsunokai, G. T., McGrath, A. R., \& Kavanagh, J. K. (2014). Online dating preferences of Asian Americans. Journal of Social and Personal Relationships, 31(6), 796-814.

Tuan, M. (1998). Forever foreigners or honorary whites? The Asian ethnic experience today. NJ: Rutgers University Press.

Tukachinsky, R. (2015). Where we have been and where we can go from here: Looking to the future in research on media, race, and ethnicity. Journal of Social Issues, 71(1), 186-199.

Tukachinsky, R., Mastro, D., \& Yarchi, M. (2015). Documenting portrayals of race/ethnicity on primetime television over a 20 -year span and their association with national-level racial/ethnic attitudes. Journal of Social Issues, 71(1), 17-38.

Wallace, M. (1994). The search for the good enough mammy: Multiculturalism, popular culture and psychoanalysis. In D. Goldberg (Ed.), Multiculturalism: A critical reader (pp. 259-268). Cambridge, MA: Blackwell.

Wang, J., Minervino, C., \& Cheryan, S. (2012). Generational differences in vulnerability to identity denial: The role of group identification. Group Processes \& Intergroup Relations, 16(5), 600-617.

Ward, W. P. (1982). The Japanese in Canada. Ottawa, ON: Canadian Historical Association. 
Wu, E. D. (2014). The color of success: Asian Americans and the origins of the model minority. Princeton, NJ: Princeton University Press.

Wu, F. (2003). Yellow: Race in America beyond black and white. NY: Basic Books.

Yamamiya, Y., Cash, T. F., Melnyk, S. E., Posavac, H. D., \& Posavac, S. S. (2005). Women's exposure to thin-and-beautiful media images: Body image effects of media-ideal internalization and impact-reduction interventions. Body Image, 2(1), $74-80$.

Yang, W. (2015, February 3). Eddie Huang against the world. The New York Times Magazine. Retrieved from http://www.nytimes.com/2015/02/08/magazine/eddiehuang-againsttheworld.html?_r=0

Yon, D. (2000). Urban portraits of identity: On the problem of knowing culture and identity in intercultural studies. Journal of Intercultural Studies, 21(2), 143-157.

Zhang, Q. (2010). Asian Americans beyond the model minority stereotype: The nerdy and the left out. Journal of International and Intercultural Communication,3(1), 20-37. 


\section{Appendices}

\section{Appendix A: Questionnaire}

Title: Media representations and the construction of racial identity

Please note: Care will be taken to protect your identity. This will be done by coding all responses and removing all names and identifying information. No participant will be identifiable in any research reports.

You have the right to end your participation in the study at any time, for any reason. You can withdraw by emailing the researcher or the research supervisor. If you withdraw from the study, all information you have provided will not be used. You may also request that certain responses not be included in the final project.

Please respond to the questions below.

Name

Age:

Program of study:

Gender:

Select one (or more) of the following categories to define yourself:

White

South Asian (e.g., East Indian, Pakistani, Sri Lankan, etc.)

Chinese

Black

Filipino

Latin American

Arab

Southeast Asian (e.g., Vietnamese, Cambodian, Laotian, Thai, etc.)

West Asian (e.g., Iranian, Afghan, etc.)

Korean

Japanese

In your own words, how would you describe your ethnic/racial identity:

Average amount of hours spent watching TV (including digital streaming services i.e. Netflix \& YouTube ) a week? 


\section{What type of TV programming do you typically watch?}

All research data, including audio-recordings and any notes will be encrypted. Any hard copies of data (including any handwritten notes or USB keys) will be kept in a locked cabinet at Carleton University. Research data will only be accessible by the researcher and the research supervisor.

The ethics protocol for this project was reviewed by the Carleton University Research Ethics Board, which provided clearance to carry out the research. If you have any ethical concerns with the study, please contact Dr. Andy Adler, Chair, Carleton University Research Ethics Board-A (by phone at 613-520-2600 ext. 2517 or via email at ethics@carleton.ca).

Researcher contact information:

Pam Lim

School of Journalism and Communication

Carleton University

Email:pamelalim@cmail.carleton.ca

\section{Supervisor contact information:}

Dr. Benjamin Woo

School of Journalism and Communication

Carleton University

Tel: $613.520 .2600 \times 1770$

Email: benjamin.woo@carleton.ca 


\section{Appendix B: Focus Group Questions}

1. Clip: All American Girl: Season 1, Ep.1 "Pilot"

- Initial thoughts/comments about the clips?

- Why do you think Margaret chooses to identify as American?

- As Canadians, can we draw similar parallels of being caught between ethnicity and nationality?

- Is Canada more accepting of diversity?

2. Clip: Fresh Off the Boat: Season 1, Ep. 1 "Pilot"

- Initial thoughts/comments about the clips?

- How would you describe Eddie? Is Eddie a stereotype?

- What does this scene communicate about the way Asians are perceived?

3. Clip: Community: Season 1, Ep. 2 "Spanish 101"

- Initial thoughts/comments about the clips?

- What's Señor Chang saying?

- Why is Señor Chang overly aggressive?

- How does the presence of stereotypes impact the way we see ourselves and interact others?

4. Clip: Kim's Convenience: Season 1, Ep. 2 "Janet's Photos"

- Initial thoughts/comments about the clip?

- How would you describe Jung?

- What do you think about the relationship between Jung and his boss?

- What differences are there in the ways Asian are portrayed in media and the was Asians are perceived in society?

5. Clip: Master of None: Season 1, Ep. 4 "Indians on TV"

- Initial thoughts/comments about the clip?

- Is it 'harder' for minorities?

- Do these clips change how you think about race? See others? See yourself?

- Do these images impact the way society is organized, the way power is distributed, and the way we treat one another? 


\section{Appendix C: List of Focus Group Codes}

1. African culture and identity

2. apolitical (Asians)

3. accents (Asians)

4. accountability (Hollywood)

5. agency (audiences)

6. Black identity

7. Black Lives Matter (activism)

8. Canadian culture/experiences

9. childhood experiences

10. Chinese (culture \& experiences)

11. controversies

12. creative freedom (Hollywood)

13. cultural history

14. cultural shift

15. diversity quota

16. doing the "right" thing (creativity verses responsibility)

17. emotional response

18. ethnic media

19. ethnicity

20. equity verses equality

21. false sense of identity

22. fetishization

23. gender stereotypes

24. generalizations

25. homogenous populations

26. humans (not humans)

27. identity

28. imagined purity

29. immigration

30. inauthentic
31. individuality

32. mainstream

33. microaggressions

34. minorities

35. misconceptions

36. multiculturalism

37. nationality

38. not ethnically identifiable

39. not represented

40. \#OscarsSoWhite

41. overly sensitive/taking it too personally

42. oversimplified

43. perception

44. politics

45. problematic

46. racialization

47. racism

48. reinforcing stereotypes

49. representation

50. resonates/relatability

51. self blame

52. sexuality

53. stable mindset/rational

54. stereotypes

55. struggle

56. $\mathrm{TV} /$ society/culture

57. unclaiming minorities

58. uncomfortable

59. universal experiences

60. where are you from?

61. yellow face 
Appendix D: Recruitment Poster

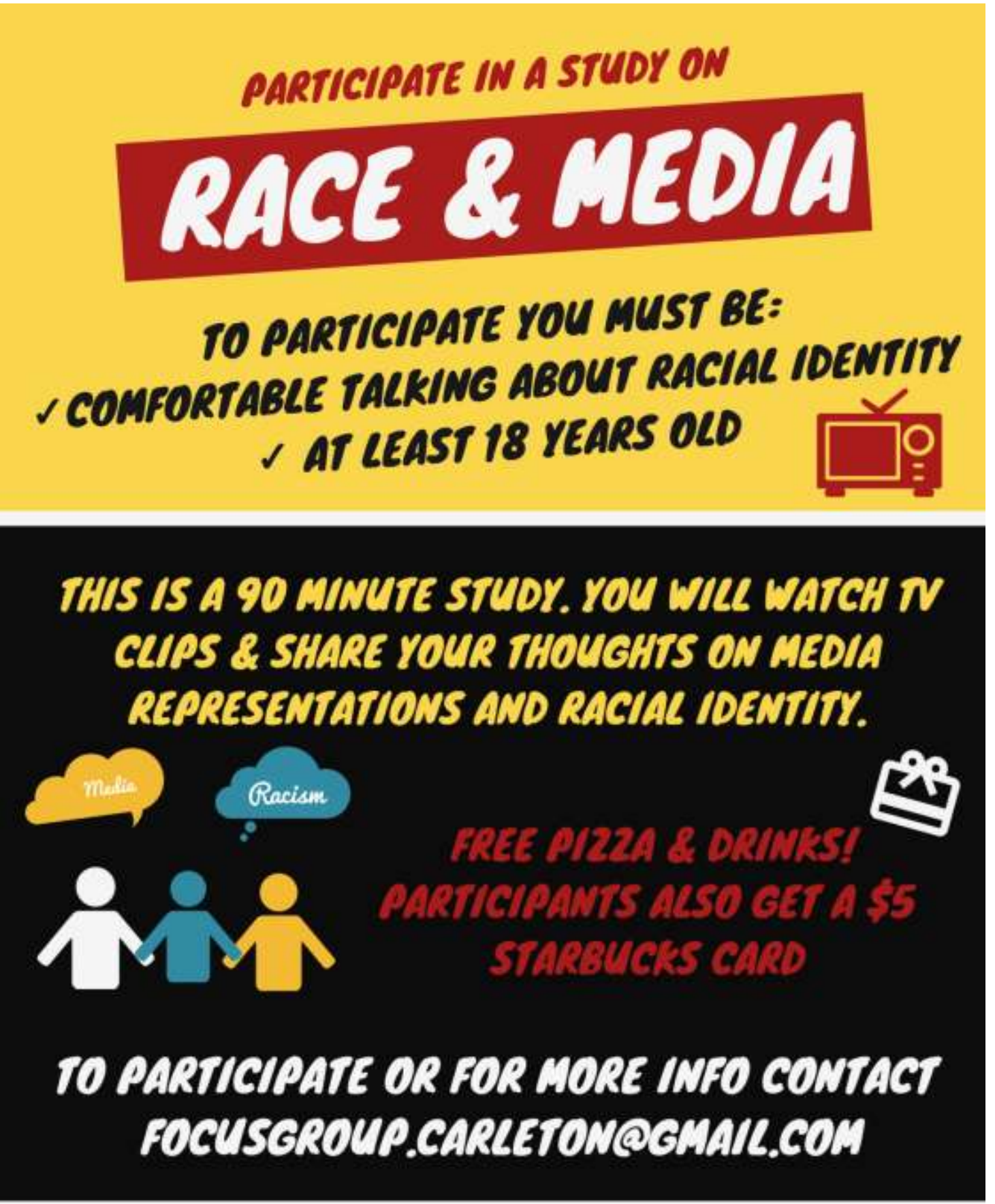

THE ETHICS PROTOCOL FOR THIS PROJECT HAS BEEN REVIEWED AMD CLEARED BY THE CARLETOW UWWERSITY RESEARCH ETHICS BOARD. IF YOU HAVE AWY ETHICAL COWCERAS WITH THE STUDY, PLEASE COWTACT DR. ANDY ADLER, CHAIR, CARLETOW UWNERSITY RESEARCH ETHICS BOARD-A (BY PHOWE AT 613-520-2600 EXT. 2517 OR VIA EMAIL AT ETHICSPCARLETOW.CAN. 